\title{
loT-commerce - opportunities for customers through an affordance lens
}

\author{
Sarah Bayer ${ }^{1}$ (D) $\cdot$ Henner Gimpel ${ }^{1,2}$ (D) $\cdot$ Daniel Rau $^{2}$ (D) \\ Received: 31 January 2019 / Accepted: 28 January 2020 / Published online: 13 March 2020 \\ (C) The Author(s) 2020
}

\begin{abstract}
Retail commerce is influenced by digital technologies at large scale. After electronic commerce and its evolution into mobile commerce, we now see that the Internet of Things (IoT), one of the most disruptive developments in recent times, is about to radically transform retail commerce from need recognition to post-purchase engagement and service. Extant literature mainly investigates technical features of IoT, missing out on a customer-centric perspective. Theoretically founded in Activity and Affordance Theories, this paper conceptualizes IoT-commerce, identifies opportunities for customers, and links them to the customer buying process. Based on an extensive literature review, twelve affordances are derived and evaluated with a sample of real-world IoT devices. All affordances offered by electronic and mobile commerce are still valid for IoT-commerce but extended by three affordances unique to IoT-commerce: context-aware services, natural interactions, and automated customer processes. Affecting all steps of the customer buying process, IoT-commerce is worth to be understood by researchers, customers, and companies.
\end{abstract}

Keywords Activity theory $\cdot$ Affordances $\cdot$ E-commerce $\cdot$ M-commerce $\cdot$ IoT

\section{Introduction}

As one of the most disruptive developments in recent times, the Internet of Things (IoT) has the power to radically transform retail commerce (Shim et al. 2019). The application of

This article is part of the Topical Collection on Internet of Things for Electronic Markets

Responsible Editor: Rainer Alt

Sarah Bayer

sarah.bayer@fim-rc.de

Henner Gimpel

henner.gimpel@ fit.fraunhofer.de

Daniel Rau

daniel.rau@ fit.fraunhofer.de

1 FIM Research Center, University of Augsburg, Universitaetsstr. 12, 86159 Augsburg, Germany

2 Project Group Business \& Information Systems Engineering, Fraunhofer FIT, Universitaetsstr. 12, 86159 Augsburg, Germany
IoT in retail commerce might even be "the most profound shift ushered in by the IoT era" (Evans 2018, p. 1). IoT refers to a multitude of smart devices that are connected to the Internet and equipped with sensors, actuators, and intelligent computing logic (Porter and Heppelmann 2014). "In time, the idea of a smartphone as a commerce device could be old news as commerce moves beyond simply portable consumer devices to include durable goods, such as refrigerators, washing machines or automobiles." (Evans 2017, p. 1). Taking the example of a smart fridge as an IoT device, first publications were discussing it already more than ten years ago (Coughlan et al. 2012; Gaur et al. 2015; Rothensee 2008). "The smart fridge has often been considered a prototypical example of applications of the Internet of Things" (Rothensee 2008, p. 123). Exemplary functionality comprises the tracking of expiry dates, recipe recommendations, and an automated reordering of groceries almost used up. Similar use cases of IoT within retail commerce are described for washing machines automatically re-ordering detergent (Deloitte 2016) or pet food dispensers (Amazon 2018b). Only recently, however, such ideas began to materialize. For instance, Samsung is now offering a smart fridge with a built-in touchscreen that allows adding items to the shopping list and then directly order 
products online (Groenfeldt 2016). Walmart filed a patent for a technology that would allow automatic re-purchase of groceries and other products without any further intervention by the customer (Nassauer 2017), an IoT idea that is already implemented in a similar way for detergent in the washing machines of Whirlpool and GE Appliances (Evans 2017). With tens of millions of sold devices, Amazon's (2018a) voice-controlled Echo is a popular example of an adopted IoT device already widely used in retail commerce (Reid 2018). This smart speaker connects to other compatible smart home devices and its ecosystem integration with the Amazon marketplace delivers seamless online shopping experiences into the homes of customers that allow the purchase of products with simple voice commands. Hence, being only theoretically discussed for many years, we now see first materialized examples of IoT in the context of retail commerce. We call this phenomenon IoT-commerce.

Ever since, commerce refers to the activity of buying and selling and, therefore, to the exchange of tangible and intangible goods at large scale (Oxford Dictionary 2018). For centuries, brick and mortar stores represented a common way of retail commerce. Driven by new technologies, new forms of commerce evolved. Increased penetration of the Internet led to the opportunity to sell and buy products online using webshops and electronic data transmission (Grandon and Pearson 2004). Revenue of this global electronic commerce (e-commerce) is anticipated to triple from 1.34 trillion USD in 2014 to 4.13 trillion USD in 2020 (Statista 2018b). With double-digit growth rates of around $21 \%$ annually, e-commerce contributes substantially to the growth of global retail sales. After the turn of the millennium, the proliferation of mobile Internet-enabled smartphones facilitated spatially independent access to online shopping (Clarke 2008). In a 2017 survey, every third online shopper stated to purchase online via a mobile device at least once per month (Statista 2018a). Along these lines, mobile commerce (m-commerce) created an unparalleled opportunity as it expanded the traditional limitations of e-commerce (Clarke 2008). Nowadays, as examples such as smart fridges and voice assistants show, we see those limitations expanding once again, driven by IoTcommerce.

Extant literature at the intersection of IoT and commerce is scarce. IoT literature mainly takes a technology-centered perspective, such as describing functionalities and applications of IoT devices (Borgia 2014), groups of IoT devices (Püschel et al. 2016), the related technology stack (Porter and Heppelmann 2014), interaction patterns between IoT devices, customers, and businesses (Kees et al. 2015; Oberländer et al. 2018), and the interplay of different stakeholders in smart service systems (Porter and Heppelmann 2014). Existing commerce literature mainly focuses on e-commerce and m-commerce.

There exists few IoT literature including customer perspectives, such as a discussion about how companies can enhance customer value with IoT devices via energy savings, property protection, proactivity, or personalized experience (Koverman 2016; Lee and Lee 2015). Nevertheless, we are not aware of a study taking the device itself as a starting point for holistically describing what IoT devices afford to customers with regard to commerce. Yet, due to the relevance of retail commerce, the substantial changes that came along with e-commerce and $\mathrm{m}$ commerce, and the disruptive potential of the IoT for retail commerce, we posit that such a perspective is valuable and a prerequisite for further examinations of IoT-commerce. Therefore, we raise the research question:

Which opportunities do Internet of Things devices provide to retail commerce customers?

Answering this research question is valuable from a theoretical and a practical perspective. In terms of theory, it links the rather disparate bodies of knowledge on commerce and IoT in a customer-centric manner. This is a basis for future research exploring the growing field of IoT-commerce. From a practical perspective, answering the research question is relevant for customers using IoT devices for shopping and companies that might want to (re-)design their customer experience in light of a new channel for customer interaction.

To answer our research question, we analyze IoTcommerce through an affordance lens embedded in Activity Theory. We use Activity Theory as a meta-theoretical lens, and we leverage the general and information systemsspecific affordance literature as a more specific theoretical foundation. Activity theory provides the socio-economic framework of rules (e.g., legislation), community (e.g., other customers), and roles (e.g., socially discriminating factors) as "minimal context for individual actions" (Beaudry and Carillo 2006, p. 429), that means the purchasing of products and services online through the means of IoT devices. Affordance Theory helps us describe individual opportunities for customers that emerge with the use of IoT devices in the context of retail commerce. Our work grounds on both academic literature in the fields of ecommerce, m-commerce, and IoT as well as on real-life examples of IoT devices that allow the purchasing of products and services. E-commerce and m-commerce literature is included in our assessment in order to evaluate whether their affordances are still valid or even strengthened in IoT-commerce. IoT literature is included in order to identify additional affordances offered by IoT devices that are not yet present since e-commerce and $\mathrm{m}$-commerce. As a validation for parsimony and 
completeness, we derive potential manifestations of the affordances within the different steps of the customer buying process and consider real-life examples of IoT devices to assess the extent of actual manifestations and check for completeness and parsimony. Our analysis revealed twelve affordances of IoT in the context of retail commerce that manifest in all steps of the customer buying process.

Second section provides the theoretical background on the evolution of e-commerce, m-commerce, and IoT-commerce and our theoretical foundation in Activity and Affordance Theories. Third section outlines the methodological approach. Fourth section presents the affordances of IoT-commerce from a theoretical perspective. A validation with real-life objects is described in Fifth section. Sixth section presents the discussion, followed by the conclusion in seventh section.

\section{Theoretical background}

In the following, we introduce the customer buying process on which our paper is based. Subsequently, we explain the evolution of commerce in three waves since the emergence of the World Wide Web in the 1990s. Thereby, we provide an overview of the development and the existing literature streams of e-commerce, mcommerce, and IoT. Afterward, we outline Activity Theory and Affordance Theory as theoretical foundations of our work.

\section{Customer buying process}

The customer buying process is a series of activities where a customer interacts in several stages with a seller or manufacturer. Models of Howard and Sheth (1969), Nicosia and Mayer (1976) and Engel et al. (1995) are often-cited models of buyer behavior including a large number of constructs, as, for instance, word of mouth, perceptual bias, and intention to purchase. Those models are taken from numerous publications as the basis for examining the influence of individual variables, such as perceived risk (Cunningham et al. 2005), or experience of the decision-maker (Frambach et al. 2007).

Our paper aims to detect opportunities of IoT within the buying process rather than to describe the underlying psychological process of the decision-maker. Therefore, we searched for a well-structured buying process focusing on the core of the process rather than on influencing variables. We selected the customer buying process of Lemon and Verhoef (2016) as it offers clear and distinguishable steps for our analysis of IoT's influence in each of those steps. The steps of this process, published in one of the leading business journals, are depicted in Fig. 1 and explained afterward.

The customer buying process of Lemon and Verhoef (2016) differentiates three major stages: pre-purchase, purchase, and post-purchase. In the pre-purchase stage, the customer interacts with other parties, as, for instance, the brand, without beginning the actual purchase. Afterward, she recognizes a need for something (need recognition), she considers buying something to satisfy this need (consideration), and she gathers information via searching product alternatives (search). In the purchase stage itself, the customer chooses one alternative (choice), orders the product or service (ordering), and pays for it (payment). The postpurchase stage summarizes the potential interaction of the customer with the brand or the environment related to the product or service after the actual purchase. The product or service is consumed or used (consumption/ usage). Furthermore, the customer can evolve into some sort of post-purchase engagement (engagement) and send service requests concerning the product or service (service request) (Lemon and Verhoef 2016). Not every buying process follows this pattern chronologically; steps can also be swapped or omitted (e.g., buying something without searching for alternatives, or engaging with the manufacturer before consuming a product).

Numerous publications take this buying process as a starting point, often to examine one or more steps in detail. Especially the steps search and choice are considered as critical steps in the process and are therefore often subject to examination in e-commerce and $\mathrm{m}$ commerce literature. For instance, Brynjolfsson and Smith (2000) disproved the assumption that lower search costs on the Internet lead to a preference of lower-priced stores instead of higher-priced stores for the same product. Trust in the online retailer (reputation, word of mouth, advertising, or prominent links from other trusted websites) or brand loyalty were found to
Fig. 1 Customer buying process adopted from Lemon and Verhoef (2016)

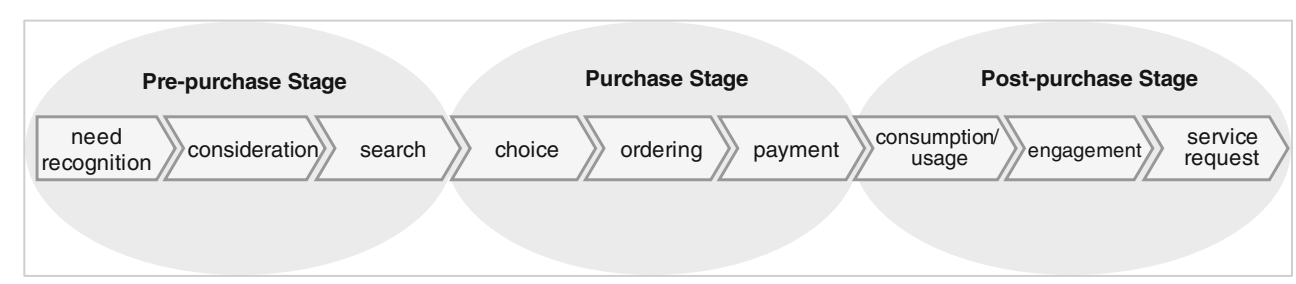


make customers choose higher-priced products (Brynjolfsson and Smith 2000; Kocas 2002). Lynch and Ariely (2000) argue that e-commerce reduces the search costs for products and product-related information, leading to the suggestion for retailers to offer differentiated goods. An investigation into search costs in context of IoT-commerce could be valuable, as customers may even outsource the search partially or completely to the IoT device, for instance, by ordering the cheapest product via voice, the product of a specific retailer, or by ordering unspecific and letting the IoT device decide based on customer's preferences. All those scenarios lead to lower search costs in IoTcommerce than in e-commerce and m-commerce that might make it even more crucial for companies to either build trust, offering highly differentiated products, or focus on price competition. Similarly, product comparison agents assist customers in decision-making leading to decreased search costs in e-commerce and unlimited availability of alternatives (Wan et al. 2007). Among different types of product comparison agents, such as evaluation agents, differentiation agents, or preference agents, IoT-commerce might especially enhance preference agents as the gathering of the underlying customer preference data significantly increases with IoT devices (e.g., shopping history, interactions with the device, music preferences, daily routines, etc.).

Based on the above-mentioned customer buying process, we now study the phenomenon of IoT-commerce as an evolution of e-commerce.

\section{The evolution of electronic commerce}

Above all, e-commerce is "a technologically driven phenomenon" (Laudon and Traver 2018, p. 38), subject to constant change due to technological advancements (Ngai and Gunasekaran 2007; Strader and Shar 1997). The emergence of new technological devices that were adopted by a critical number of private users and that inhibit the possibility to support each step of the customer buying process or only parts of it influenced the way retail commerce is conducted. We see three major waves of commerce initiated via the widespread use of new technologies: e-commerce, enabled by desktop devices (e.g., Personal Computer) connected to the Internet; m-commerce, enabled by mobile devices (e.g., smartphones and tablets) connected to the Internet; and IoT-commerce, enabled by IoT devices (e.g., voice assistants) connected to the Internet.

Before the debut of mail-order catalogs and teleshopping, brick and mortar stores were the linchpin of buying for all kinds of products and services (Miles 1990). With the appearance of the World Wide Web in the early 1990s, the base for ecommerce was set (Turban et al. 2015). E-commerce "suggests that consumers access a website through a computer terminal" (Maity and Dass 2014, p. 35). The literature discusses several aspects that distinguish e-commerce from traditional commerce. Electronic marketplaces, for example, electronic payment or electronic marketing via social networks, allow the "participating buyers and sellers to exchange information about prices and product offerings" (Alt and Klein 2011; Strader and Shar 1997, p. 187; Turban et al. 2015). When O'Reilly Media first used the term 'Web 2.0' in 2004, they described the evolution of the World Wide Web toward social media, facilitating information sharing between customers, for instance, in social networks or by writing reviews (Butler and Peppard 1998; Turban et al. 2015). Along these lines, increased information density allows customers to instantly acquire detailed product information. Additionally, e-commerce enables customization of products and personalization of services (Butler and Peppard 1998; Turban et al. 2015).

Academic literature in the field of e-commerce is rich, comprising topics like technical aspects (e.g., Guttman et al. 1999; Lee and Lee 1993; Xiao and Benbasat 2007), behavioral issues such as consumer behavior and technology acceptance (e.g., Gefen et al. 2003; Klopping and McKinney 2004; Liang et al. 2011), and business models (e.g., Aldridge 1998; Kraemer et al. 2000; Timmers 1998). Several literature reviews synthesize extant e-commerce research streams from different perspectives. For instance, Ngai and Wat (2002) screened 275 articles published between 1993 and 1999 and clustered them into four categories: 'application areas,' 'technological issues,' 'support and implementation,' and 'others'. Chua et al. (2005) took a stakeholder perspective and identified 'customers' and the 'internal organization' as stakeholders with the most attention in e-commerce research, whereas 'suppliers', 'indirect stakeholders', 'investors', and 'regulators' receive less interest. In their review of electronic markets research, Alt and Klein (2011) identified three perspectives: 'economic environment,' 'governance mode,' and 'business model'.

With the advent of more and more mobile devices in the 2000s, m-commerce took its course (Wirtz 2018). Mcommerce describes the possibility "to purchase goods anywhere through a wireless Internet-enabled device" (Clarke 2008, p. 133; Maity and Dass 2014). Mobile devices in the context of m-commerce are portable devices with wireless Internet access that, by nature, are designed to be moved with its users, such as smartphones and tablets (Junglas and Watson 2003; Turban et al. 2015). Furthermore, mobile devices enable location-based services and advertisement that is individually adapted to the local context. For instance, the Uber platform allows to call a taxi to the current GPS location of the customer and estimates its time of arrival (Turban et al. 2015). Although some functions, such as user accounts for desktop PCs and synchronization of user accounts on different 
devices, offer strong personalization possibilities in e-commerce, personalized advertising in $\mathrm{m}$-commerce is typically easier as mobile devices are used by only one person (Turban et al. 2015). Mobile devices experienced their upswing after the emergence of desktop PCs for e-commerce. However, in some regions m-commerce unfolded first, followed by later adaption of e-commerce. Furthermore, we observe that the beginning of e-commerce is product-oriented, meaning that products of brick-and-mortar stores were bought via the Internet, whereas the ongoing change from productorientation towards service-orientation initiated a change in eand m-commerce towards services. Some characteristics of ecommerce expand in m-commerce, and some key attributes of $\mathrm{m}$-commerce, such as location-based services, lead to specialized business models, especially in the service domain (Turban et al. 2015). In our paper, we examine products, that means "something that is made to be sold, usually something that is produced by an industrial process" (Cambridge Dictionary 2019a), services, that means "business activity that involves doing things for customers rather than producing goods" (Cambridge Dictionary 2019b), as well as hybrid offers of products and services.

Similarly to e-commerce, research streams of m-commerce relate to technical aspects (e.g., Lee and Benbasat 2004), behavioral research (e.g., Schierz et al. 2010), and business models (e.g., Tsalgatidou and Pitoura 2001). However, the total number of publications is significantly smaller compared to e-commerce. M-commerce research focuses on the additional features provided by mobile devices compared to desktop devices, for instance, location-based services (e.g., Rao and Minakakis 2003). There are only a few literature reviews of m-commerce. For instance, Ngai and Gunasekaran (2007) synthesize m-commerce research streams by the categories of 'm-commerce theory and research', 'wireless network infrastructure', 'mobile middleware', 'wireless user infrastructure', and 'm-commerce applications and cases'. Groß (2015) clustered $\mathrm{m}$-commerce literature into the three categories of 'online distribution channel', 'advanced technology for in-store shopping', and 'technology perspective'.

The overview of existing research about e-commerce and $\mathrm{m}$-commerce shows that authors frequently take a technical point of view (e.g., technical aspects of e-commerce/m-commerce, technological issues, wireless network infrastructure, support and implementation, mobile middleware), which is not the focus of our paper. Within our research, we concentrate on publications that describe commerce from a customer's point of view or in such a general way, that implications for customers can be derived. Furthermore, we assume that the research streams of technical aspects, behavioral research, and business models that flourished through the waves of ecommerce and m-commerce are likely to be continued for IoT-commerce. Our research on IoT-commerce is located at the intersection of all three research streams as we use an affordance lens to derive opportunities from technical features of IoT devices that impact customer behavior and potentially enable innovative business models.

With the emergence of IoT devices, also called smart connected devices, another option to purchase online arises next to desktop devices (e-commerce) and mobile devices (m-commerce). IoT describes the phenomenon that physical objects are integrated into the networked society, leading to a fusion of the physical and digital world (Huber et al. 2017; Rosemann 2014; Wortmann and Flüchter 2015). Two central aspects turn devices into IoT devices. First, the Internet connection, enabling the device to send and receive data. Secondly, sensors and/or actuators enable those objects to be "tracked, coordinated, or controlled across a data network or the Internet" (McKinsey 2013, p. 52). The IoT device equipped with sensing and acting capabilities captures and aggregates data, and potentially takes action (Borgia 2014). Therefore, the IoT device possesses certain intelligence to act and make decisions independent of human agency (Gaskin et al. 2014; Porter and Heppelmann 2014). In short, IoT connects information technology and physical objects, leading to new products and services (McKinsey 2013; Uckelmann et al. 2011). Having reviewed different definitions of IoT (Huber et al. 2017; McKinsey 2013; Uckelmann et al. 2011; Wortmann and Flüchter 2015), we find the definition of Kees et al. (2015) most suitable for this paper as it gives a good understanding of IoT from the viewpoint of the user, which is in our context the customer. In line with Kees et al. (2015) we define:

IoT devices are a multitude of physical objects, equipped with sensors, actuators, and/or computing power connected to the Internet via communication technology, and enabling interaction with and/or among those objects.

Personal computers, laptops, tablets, and mobile phones are traditional physical devices with sensors, computing power, and typically an Internet connection. These devices are IoT devices. However, commerce solely relying on the aforementioned devices commonly used in e-commerce and $\mathrm{m}$ commerce does not qualify as IoT-commerce. Rather, IoTcommerce denotes retail commerce using non-traditional smart connected physical devices such as voice assistants, smart washing machines, and smart thermostats. With the help of voice assistants, one can purchase new products within seconds via voice command; with a smart washing machine, one can automatically reorder detergent right before it is used up; with a smart thermostat, temperature and therefore energy consumption can be optimized automatically without assistance of the owner leading to an adjusted amount of energy purchase, especially in cases where heating and cooling is performed with electricity. This implies that IoT-commerce 
is not a radical replacement of e-commerce and/or m-commerce, but can be seen as an "evolution rather than a revolution" (Evans 2017, p. 1). Hence, we use the following definition of IoT-commerce:

IoT-commerce relates to the purchasing of products and services online via the use of IoT devices whose technical features afford new opportunities to retail customers.

Information systems research discusses features, interactions, and recommendations of IoT devices (e.g., Fleisch et al. 2009; Oberländer et al. 2018; Song et al. 2017). In marketing, interactions between the IoT device and the customer are discussed related to customer and object experiences (e.g., Hoffman and Novak 2018; Kozinets 2019). Under the terms "ubiquitous commerce", computer scientists examine the ubiquity and pervasiveness of IoT-commerce from a technical and opportunity-centered perspective, describing potential applications of IoT in commerce (e.g., Bhajantri et al. 2015; Chunxia et al. 2010; Fox et al. 2006; Sanchez-Pi and Molina 2009). Examples of IoT devices used in retail commerce are already widely discussed in practice (e.g., Farhad 2018; Heatman 2018), but scientific research embedded in existing theories is still scarce in this field.

\section{Activity theory}

Our work of IoT devices in retail commerce builds on Activity Theory, which is located at the intersection of behavioral and social sciences, as it "provides a high-level contextual perspective of human behavior" (Beaudry and Carillo 2006, p. 429). Activity Theory formalizes the interaction of a subject with the world. The conceptualization of Activity Theory, especially regarding activity systems of individuals, traces back to Vygotsky (1980) and Leont'ev (1978) and is also known as the mediated-action perspective (Kaptelinin and Nardi 2012). In particular, it describes how a Person (P) interacts with an Object $(\mathrm{O})$ via the use of Tools $(\mathrm{T})$ (BenbunanFich 2019). The Person is typically an acting human being. The Object is affected by the action of the Person (BenbunanFich 2019). Kaptelinin (2005) differentiates between physical objects and intangible constructs such as commonly accepted facts or socially and culturally defined properties that can also represent the Object within Activity Theory. The Object, therefore, possesses an ambiguous nature (physical vs. intangible). Ultimately, the Object is the motive for the actions of a goal-directed Person (Kaptelinin 2005). The Tool mediates the human activity of the Person, contributes to accomplishing the intended goal, and triggers an effect on the Object. The nature of Tools can be both physical such as technology (Karanasios and Allen 2014) or psychological such as language, symbols, and mental models (Allen et al. 2013; Karanasios and Allen 2014). Another typology of tools by Hasan and Kazlauskas
(2014) differentiates between primary (physical), secondary (language, mental models), and tertiary tools (communities, context, or environment). Typically, the relationship between Person, Tool, and Object is depicted as ' $\mathrm{P} \Leftrightarrow \mathrm{T} \Leftrightarrow \mathrm{O}$ '. Later, Engeström (1987) extended this triad to incorporate the socially embedded concepts of rules, community, and roles (Beaudry and Carillo 2006).

As a well-articulated concept for descriptive purposes, Activity Theory is a theory for analysis and explanation of the world (Benbunan-Fich 2019; Gregor 2006) with activities as the unit of analysis (Engeström 1987). In its original conceptualization by Vygotsky (1980) and Leont'ev (1978), Activity Theory did not particularly comprise digital technologies. Against this backdrop, researchers introduced Activity Theory into the domain of Human-Computer Interaction to better understand how technology mediates human activities (Kaptelinin and Nardi 2012; Nardi 1996). Until now, two major Information Systems (IS) research streams evolved around Activity Theory, one to better understand IS intervention and the other "more connected with the fields of design and development, and the technical side of IS" (BenbunanFich 2019, p. 3). As a cross-disciplinary framework, Activity Theory contributes to a human-oriented understanding of the collaboration and interaction between humans (i.e., Person) and IS (i.e., Tool). It allows investigating different types of human practices on both an individual and social level (Nardi 1996).

IS research has started to utilize Activity Theory in the domain of e-commerce. For instance, Chaudhury et al. (2001) built their work on Activity Theory to understand customer experiences in the Internet and to support successful web development. Johnston and Gregor (2000) rely on core elements of Activity Theory to conceptualize industry-level activity that aims at explaining certain aspects of supply chain e-commerce technologies. Beaudry and Carillo (2006) organize their review of B2C literature along with the Activity Theory framework. In this paper, we build on Activity Theory as a foundation to explore the affordances of IoT devices in the customer buying process. In the words of Activity Theory, our goal-directed Person is the customer with her goal to satisfy her need via online purchase. By the use of an IoT device as a primary physical Tool, this customer interacts with a seller, manufacturer, or service provider that can be seen as Object. Her interaction is embedded in the socio-economic framework of rules (e.g., legislation), community (e.g., peer customers), and roles (e.g., social demography).

\section{Affordance theory}

Repeatedly, Activity Theory is combined with the concept of affordances as they are the relational property of interaction within the Person-Tool-Object triad (Benbunan-Fich 2019). Whereas instrumental affordances relate to the handling 
('P $\Leftrightarrow \mathrm{T}$ ') and effect ('T $\Leftrightarrow \mathrm{O}$ ') of the Tool, supplemental affordances relate to auxiliary activities such as maintenance of the Tool (Benbunan-Fich 2019). The concept of affordances was first brought up in ecological psychology. It originates from Gibson (1979) who used the verb 'afford' to describe what the environment offers to an animal. He refers to a subject (animal) that is provided with affordances from an object (object within the environment). Gibson (1979) associates properties of objects with affordances that guide the actions of the subject. He, therefore, emphasizes the complementarity of a subject and its environment (Benbunan-Fich 2019). Later, Norman (1988) introduced affordances into design theory and the domain of Human-Computer Interaction. In the beginning, his work centered mainly on his designoriented belief that objects and tools should be designed for their intended use - in a way that the user can anticipate the object's affordance. He then abstracted from the physical nature of objects and applied the concept of affordances on intangible artifacts and software user interfaces (Benbunan-Fich 2019). Therefore, he rather took a design perspective on affordances. In further work, Norman (1999) differentiated between perceived and real affordances. Whereas real affordances refer to the actual properties of an object or artifact, the perceived affordances are those that are noticeable for subjects such as human beings by providing cues for proper operation and usage. Depending on the individual, perceived affordances may vary among a heterogeneous group of users.

Based on the classification by Norman (1999), there were attempts to further extend the classification of affordances. Hartson (2003), for instance, suggested a differentiation between cognitive (i.e., perceived affordances), physical (e.g., real affordances), sensory (i.e., properties to feel, see hear, etc.), and functional (i.e., support in a task relating to a higher purpose) affordances. Vyas et al. (2017) conceptualize affordances at a much broader scope by incorporating social and cultural aspects. However, most authors interpret the relationship between subject and object as the core of the Affordance Theory (Bærentsen and Trettvik 2002; Benbunan-Fich 2019; Gaver 1991, 1992; Gibson 1979; Kaptelinin and Nardi 2012; McGrenere and Ho 2000; Norman 1999). Affordances materialize in the interaction between the subject (e.g., Person/human) and object (e.g., IoT device). Following this logic, affordances are possibilities for goal-directed actions of goal-oriented actors with regard to an object (Markus and Silver 2008). The affordance perspective can, therefore, provide a useful lens to analyze (emerging) technologies in a user-centered manner (Gaver 1991; Leonardi 2011).

In the following, we rely on the general concept of affordances but do not further differentiate between different types such as cognitive, physical, sensory, and functional affordances of IoT-commerce. We use the term 'IoT-commerce affordances' for affordances of IoT devices directed to retail commerce customers and apply the same analogy on 'e-commerce affordances' and 'm-commerce affordances'. Furthermore, our affordances might not yet all be perceived by customers. Hence, we focus on real affordances for now, though future research on the differences to perceived affordances might be very useful. Perceived affordances might then be actualized by the customer within the process of purchasing products and/or services online.

\section{Methods}

To answer our research question which opportunities IoT devices provide to retail commerce customers, we pursued a two-step approach in which theory development is followed by validation. For theory development, we identified the affordances of e-commerce, m-commerce, and IoTcommerce based on academic literature. For validation, we conducted a twofold analysis to ensure parsimony and completeness. Below, we provide details on each methodological step.

In the first step of theory development, we reviewed extant literature to collect real affordances of e-commerce, m-commerce, and IoT-commerce. As literature on the established research domains of e-commerce and $\mathrm{m}$-commerce is rich, we focused on articles synthesizing existing research. By contrast, the IoT phenomenon is not yet well researched. Therefore, we did not further restrict our search to literature review articles about IoT but conducted our search in the whole IoT domain. We used the following combined search term for titles and abstracts: $\{$ \{ "e-commerce" OR "electronic commerce" OR "m-commerce" OR "mobile commerce" OR "online shopping" OR "electronic shopping" OR "mobile shopping" OR "e-business" OR "electronic business"\} AND \{review OR affordance\}\} OR \{iot OR "internet of things"\}. As advised by Webster and Watson (2002), we performed our literature search in leading IS journals, namely the AIS Senior Scholars' Basket of Eight ${ }^{1}$ (2018). Furthermore, following Webster and Watson (2002), we expanded our search beyond core IS journals. We included the journal 'Electronic Markets' due to its inherent connection to electronic commerce, and other peer-reviewed journals specifically addressing the electronic commerce domain. ${ }^{2}$ Furthermore, we integrated a

\footnotetext{
${ }^{1}$ Considered journals according to AIS (2018): European Journal of Information Systems, Information Systems Journal, Information Systems Research, Journal of AIS, Journal of Information Technology, Journal of MIS, Journal of Strategic Information Systems, MIS Quarterly

${ }^{2}$ Considered journals: Electronic Commerce Research, Electronic Commerce Research \& Applications, International Journal of Electronic Commerce, Journal of Electronic Commerce in Organizations, Journal of Electronic Commerce Research, Journal of Organizational Computing \& Electronic Commerce
} 
marketing perspective due to its close connection to commerce. We searched in leading marketing journals ${ }^{3}$ for "internet of things" OR "IoT". To include discussions about IoT in computer science and electrical engineering, ${ }^{4}$ we additionally searched for the corresponding terms: " "e-commerce" OR "electronic commerce" OR "m-commerce" OR "mobile commerce" OR "online shopping" OR "electronic shopping" OR "mobile shopping" OR "e-business" OR "electronic business"\} AND \{“ambient intelligence" OR "pervasive computing" OR "ubiquitous computing"\}.

The search resulted in 180 articles on which two authors independently performed a title and abstract screening. An article was considered relevant if it mainly dealt with e-commerce, m-commerce, or IoT, provided an overview of the evolution of at least one of those fields, or presented one specific affordance in detail. An article was marked for detailed examination if at least one researcher classified it as relevant. With this research strategy within IS journals, commerce-related journals, marketing journals and the domain of computer science, we "accumulate a relatively complete census of relevant literature" (Webster and Watson 2002, p.xvi).

As a second step, two researchers independently examined the full text of the remaining 49 relevant journal articles in detail and highlighted affordances of e-commerce, m-commerce, and IoT-commerce. We identified phrases (e.g., '24/7 availability'), sentences, passages, and the whole topic of an article (e.g., 'user-generated content in the form of online product reviews') as affordance if they satisfied the following criterion: The aspect is peculiar to e-commerce, m-commerce, or IoT-commerce, therefore helps identify the respective phenomenon, and offers direct or indirect possibility for action to the customer. For each affordance, we documented its presence within e-commerce, m-commerce, and/or IoT-commerce. Relatively few publications on IoT in the context of commerce revealed that IoT-commerce affordances cannot be compiled solely on commerce-related literature. Hence, during the paper screening, we also highlighted (technical) features and aspects of the very nature of IoT devices that lead to affordances for customers.

In intense discussions, we consolidated all aspects highlighted during the paper screening, finally leading to twelve affordances as presented in the next section. Within this consolidation, same and similar highlighting was merged into one affordance (e.g., '24/7 availability' and 'temporal independence'), the granularity level of all affordances was harmonized (i.e., not too specific and not too generic affordances), an explanation comprising all relevant aspects

\footnotetext{
${ }^{3}$ Considered journals: Journal of Marketing, Journal of Marketing Research, Journal of Consumer Research

${ }^{4}$ Database used: ieeexplore.ieee.org
}

identified in academic literature was compiled, and the number of affordances was decreased to achieve conciseness.

For validation with real-life IoT devices regarding completeness and parsimony of our theory, we chose a twofold approach. We drew a sample of 337 IoT devices that were obtained from three studies that provide extensive literature reviews of IoT devices in scientific and grey literature: Oberländer et al. (2018), Püschel et al. (2016), and Brandt et al. (2017). For our research, we considered only those IoT devices that either enable the purchase of products and services by itself (e.g., Amazon Echo) or strongly influence the type, quality, quantity, or ordering time of goods purchased (e.g., Nest thermostat), resulting in 35 relevant IoT devices. Therefore, other devices such as smart locks (e.g., Lockitron), smart mattresses (e.g., Luna), or smart home monitoring systems (e.g., Sentri) were not considered. Similar IoT devices (e.g., Amazon Echo Dot and Amazon Echo Plus or Nest thermostat and smart irrigation controllers) were grouped, resulting in five major groups of these 35 IoT devices relevant for IoT-commerce as presented by Table 1 . The overview contains devices for the purchase of both products and services. Further, those purchases are made either explicitly (i.e., purchase immediately initiated by the device) or implicitly (e.g., optimization of energy consumption which transitively influences the amount of energy purchased).

To check for parsimony, we evaluated whether all twelve identified affordances do already manifest in reality. We derived manifestations of affordances by subsequently applying each affordance to each step of the customer buying process. If the examined real-life examples of IoT devices confirmed that an affordance provides a possibility for action to the customer or removes her need to act in one of those buying process steps, we documented the respective manifestation and provided an exemplary description of this opportunity directed to the customer. Our overview of affordances presented in the next section only comprises IoT-commerce affordances that already manifest in several steps of the customer buying process as supported by existing real-life examples of IoT devices.

To check for completeness, we chose the reverse approach and examined real-life examples of IoT devices in detail. For each device, we analyzed its influence on each step of the customer buying process. If an IoT device has an influence on one step of the buying process and provides an immediate opportunity to the customer in this step, then we checked whether this opportunity is already covered by the identified twelve affordances. As all opportunities provided by real-life IoT devices were already covered by the IoT-commerce affordances we identified, we did not have to add further affordances.

The following fourth section presents twelve affordances of IoT-commerce as a result of the theory development, followed by validation with real-life objects in fifth section. 


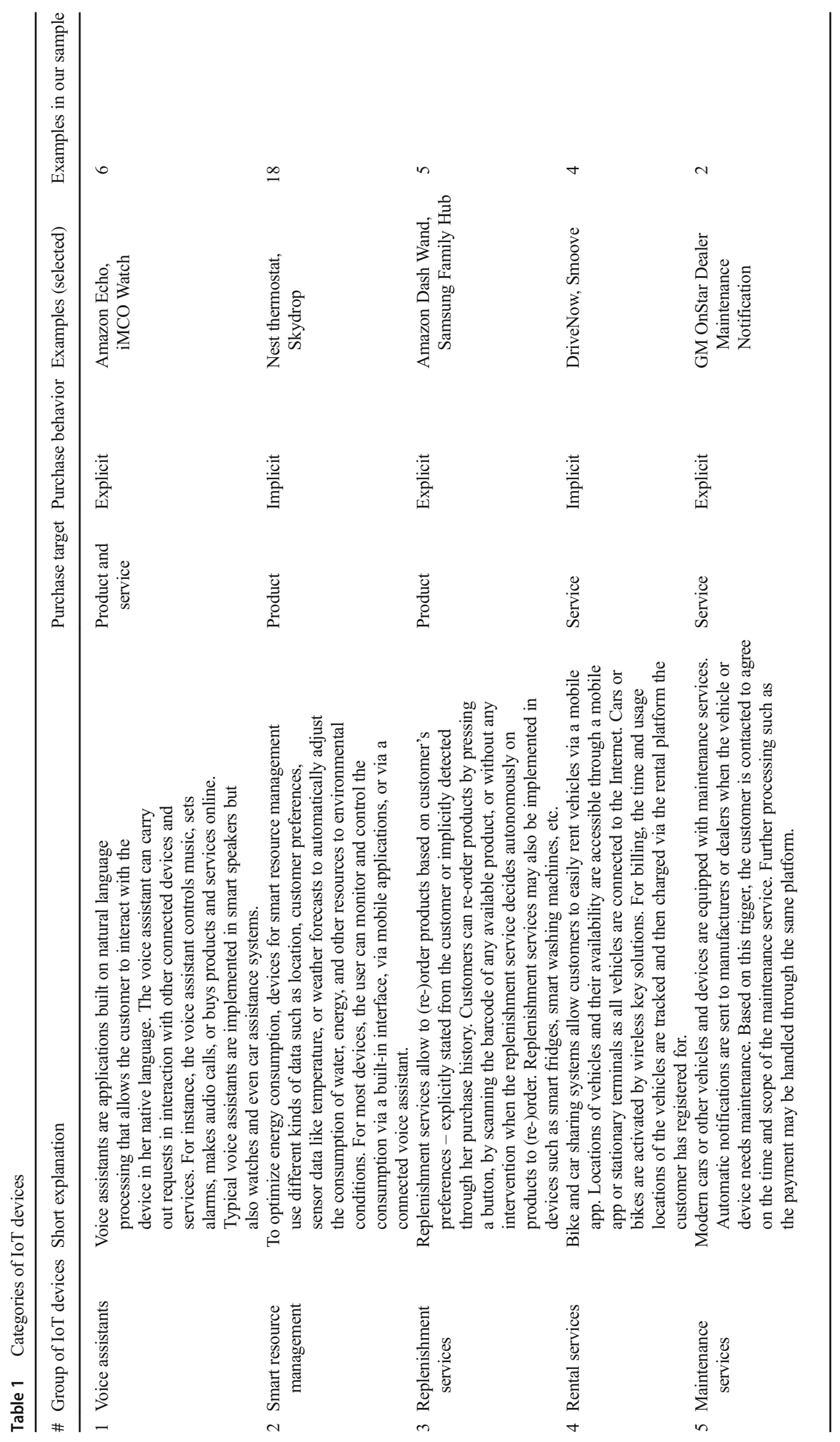




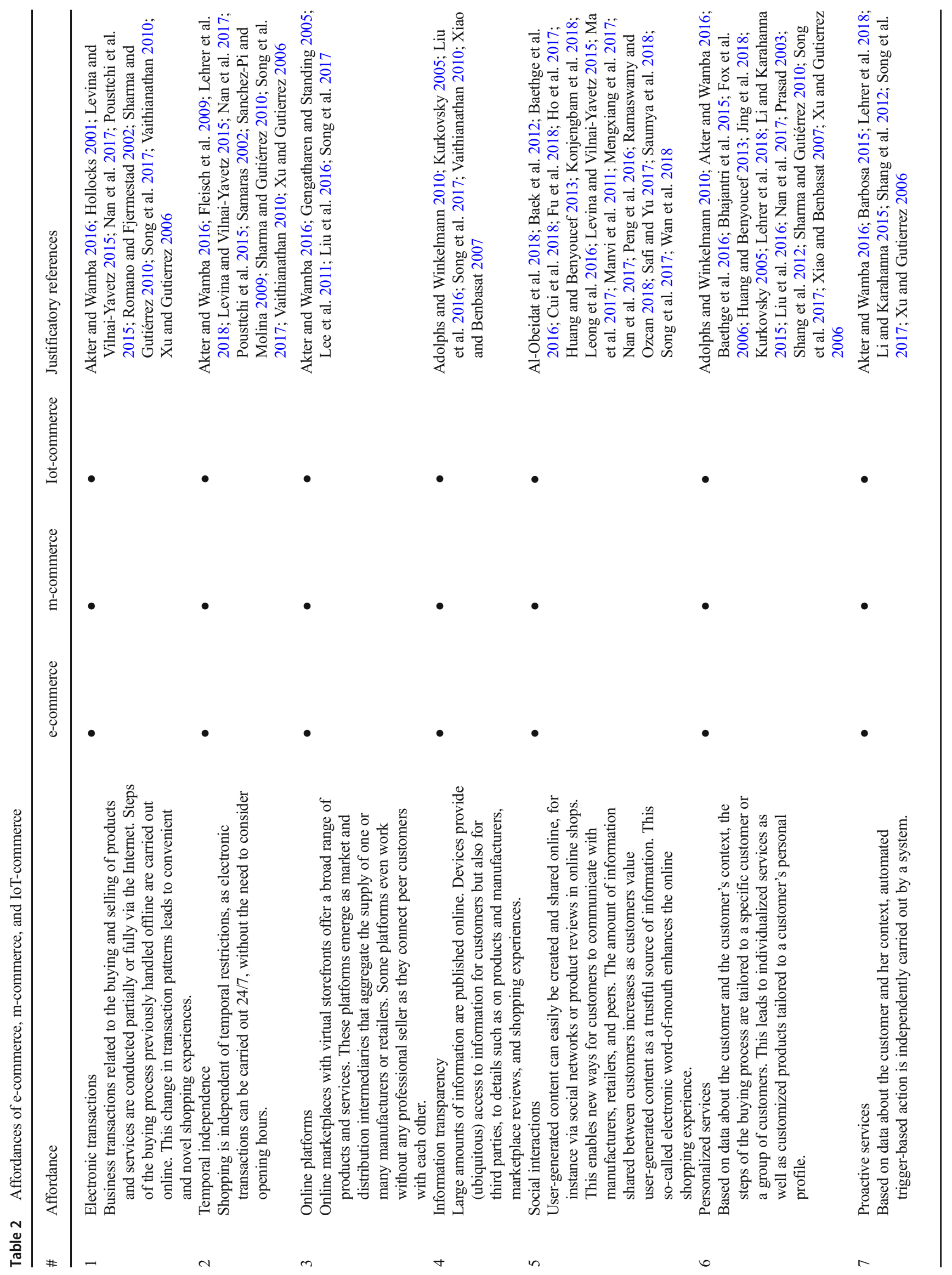




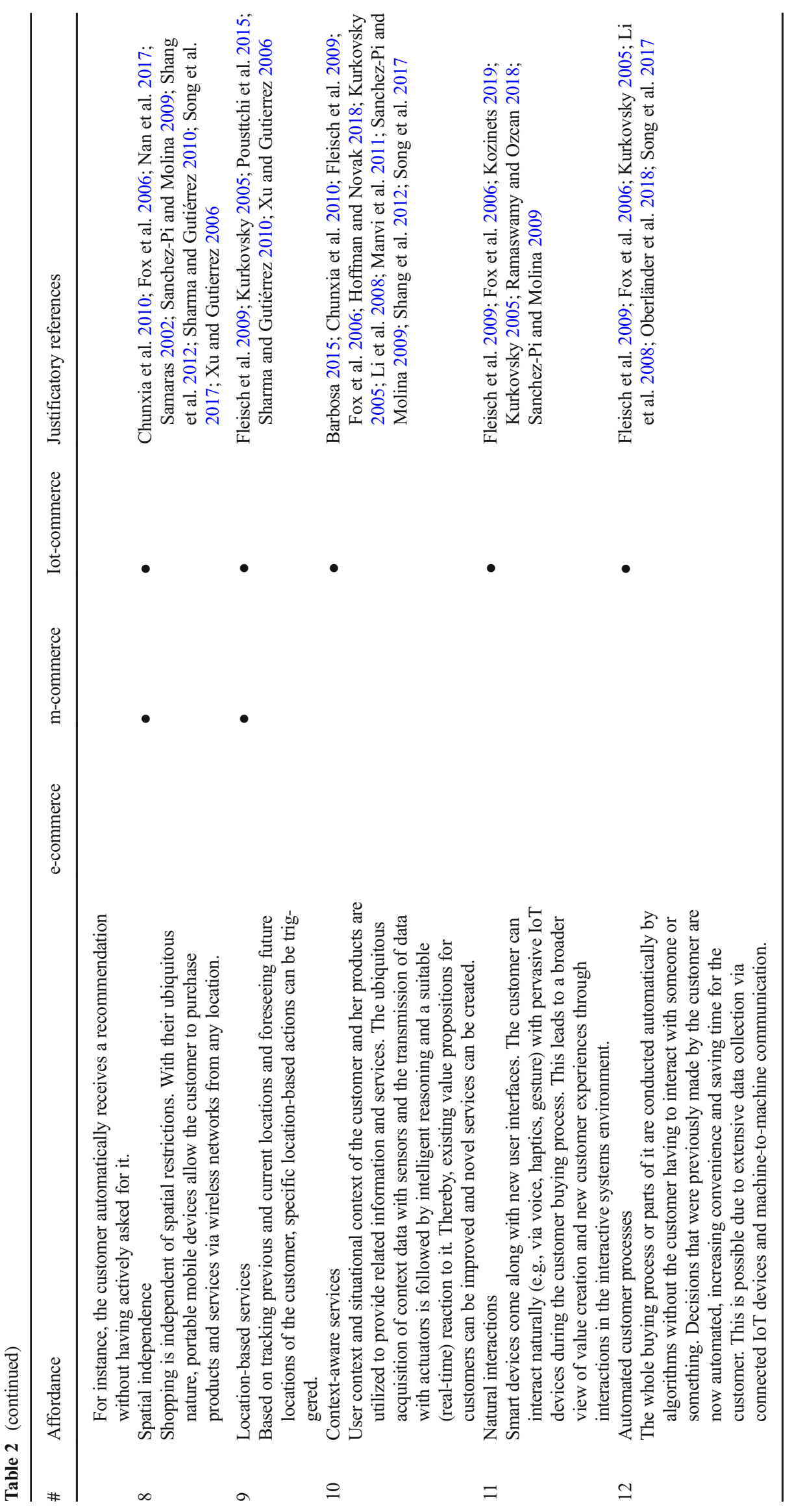




\section{Affordances of loT-commerce}

The main result of our paper is the identification of affordances for IoT-commerce as shown in Table 2. For each affordance, we provide a definition based on the aspects raised in literature. Furthermore, we state with a bullet (' $\bullet$ ') in the third, fourth, and fifth column in which wave of commerce an affordance takes effect. Interestingly, no affordance disappeared from one wave to the following ones. All affordances that emerged with e-commerce can still be found in the following two waves and all affordances that emerged with $\mathrm{m}$ commerce are also offered by IoT-commerce. Some affordances that are presented to only occur within the second or third wave can also have an effect on the previous waves. For instance, the extensive automation of customer processes due to smart algorithms primarily emerged with the new opportunities of data collection by IoT devices (e.g., by their sensors), but is now also reactively influencing e-commerce and $\mathrm{m}$-commerce. However, in this section, we focus on IoTcommerce affordances and their respective origins and do not mark retrospective effects on e-commerce and $\mathrm{m}$-commerce. All affordances based on the 49 relevant articles of our literature review are presented with justificatory references.

The twelve affordances are split into seven that primarily arose with e-commerce, two affordances that primarily emerged with m-commerce, and three affordances that experienced their upswing with IoT-commerce. IoT-commerce itself is characterized by all of the twelve affordances as those of previous waves still remain valid. However, the sheer number of affordances might suggest that e-commerce is the most important wave of commerce. Though the Internet accessible through desktop computers resulted in a substantial change in retail commerce, IoT-commerce also holds disruptive potential. A rapidly growing number of connected devices and first manifestations of IoT affordances in retail commerce demonstrate that IoT-commerce is about to radically transform the way online purchases are made. Hence, an investigation into the affordances of IoT-commerce is truly valuable. The three affordances that distinguish IoT-commerce from the previous waves of commerce result from technical features of IoT devices such as described by the editorial of Fleisch et al. (2009). Our paper goes beyond the described technical features, applies IoT functionality to the context of retail commerce, and incorporates recent developments and more specific concepts of the IoT phenomenon since the publication of Fleisch et al. (2009). The first affordance originating from IoT-commerce are context-aware services that are enabled by sensors and actuators of the IoT device, as the environment can be observed and triggers for further action can be set based on sensor data. For instance, a smart thermostat might detect the need to heat a room and influence the amount of energy bought before the customer recognizes this need. As a second addition, IoT devices also allow natural interaction with voice or gesture. For instance, voice assistants enable online shopping mainly controlled by voice commands. The third addition relates to intelligent algorithms in IoT devices that are used to automate customer processes. Decentralized intelligence embedded in IoT devices on the customer-side

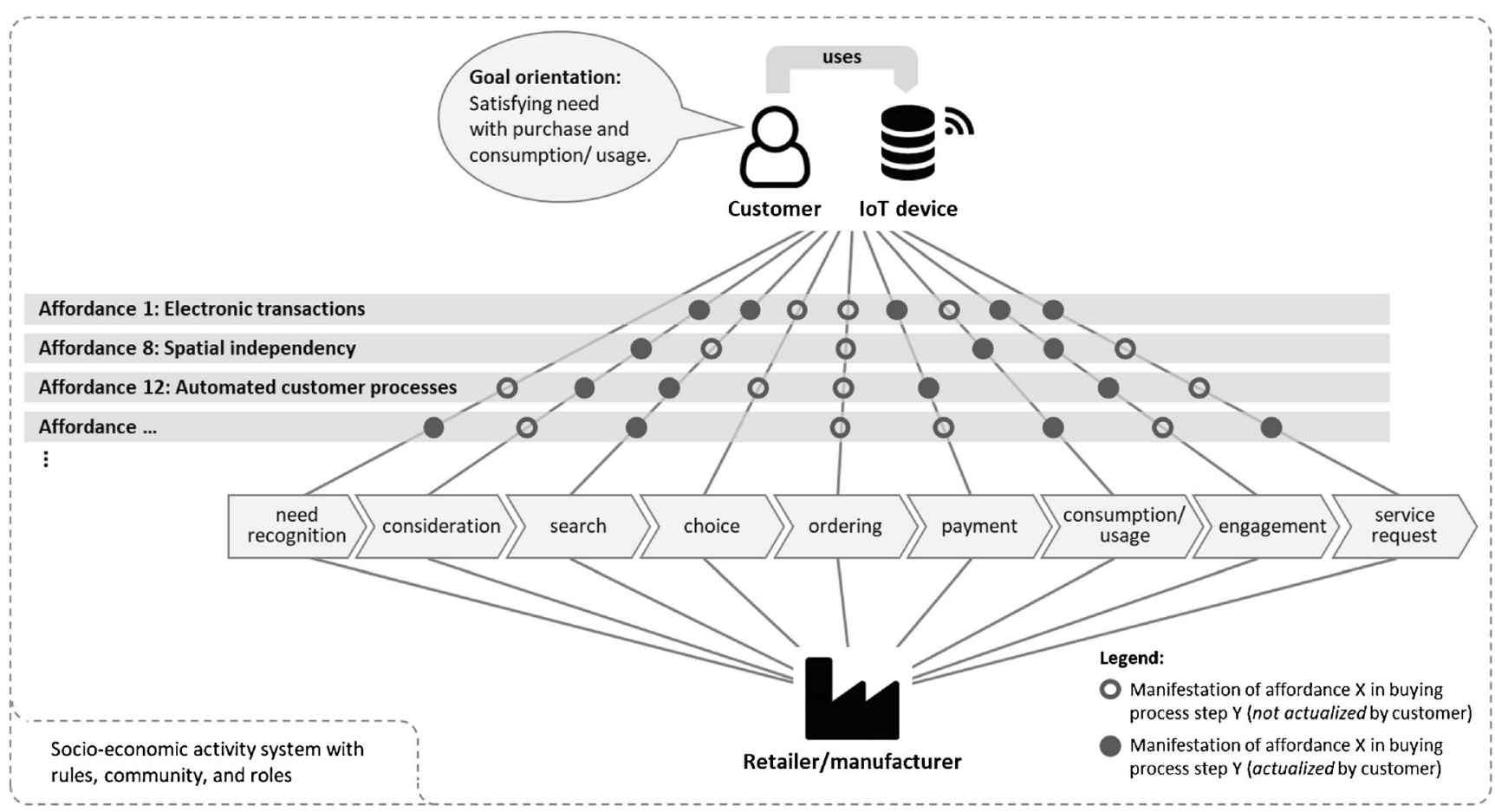

Fig. 2 Activity system of IoT-commerce with affordances and its manifestations 


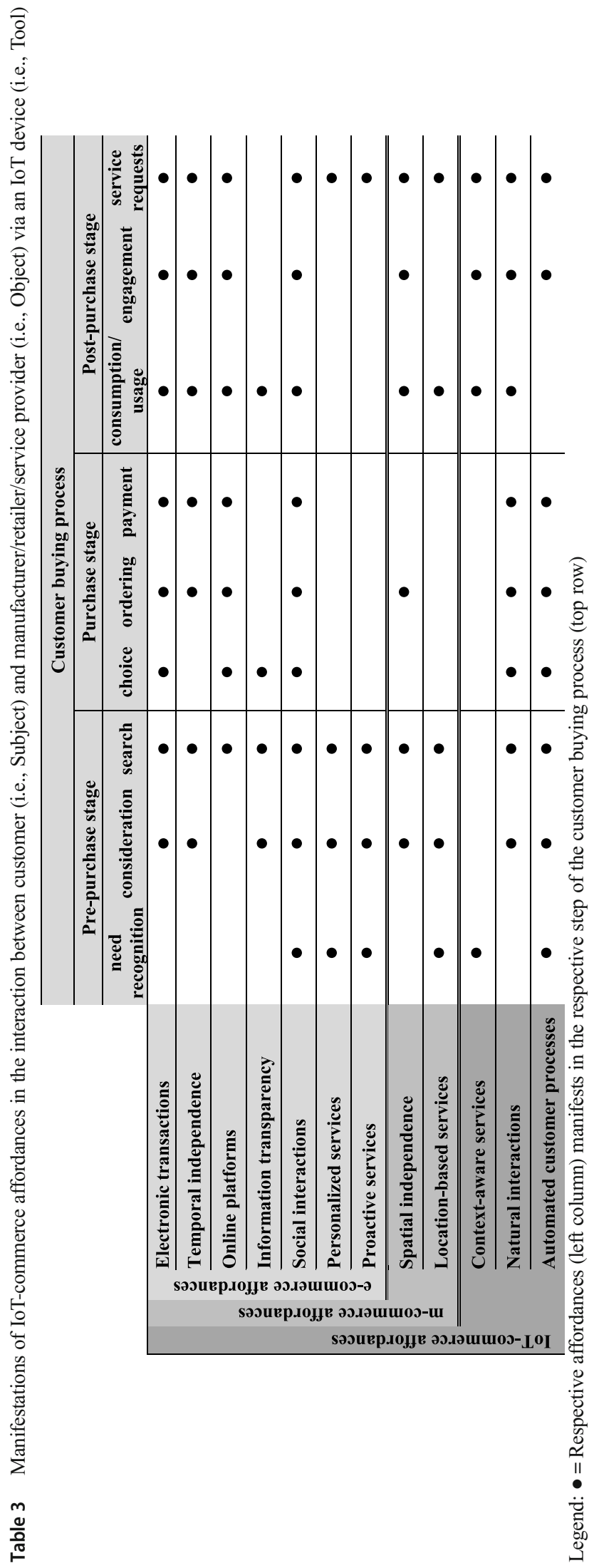


primarily emerged with IoT devices. Recommender systems and shopping agents that came up with e-commerce also inhibit intelligence but are usually situated on the supplier-side, whereas smart algorithms in IoT devices, enabling the actual automation of processes, are anchored on the customer-side. IoT devices, such as smart fridges, frequently lever this intelligence to decide autonomously when to re-order groceries.

The other affordances still remain valid, such as information transparency, which developed with e-commerce. It should be pointed out, however, that this also means that associated biases may still remain valid. Besides the positive effect of increased information transparency in e-commerce and m-commerce, research shows the existence of information bias. For instance, readers of online product reviews may be effected by sequential bias (Wan 2015) and self-selection bias (Li and Hitt 2008). The extent to which these biases still exist in IoT-commerce strongly depends on the specific setting with its inherent decisions (IoT device is autonomously deciding on a purchase vs. customer is deciding and purchasing via an IoT device). To check for the existence of biases in IoTcommerce is not the focus of this paper but is strongly recommended for future research.

To visualize the role of affordances in the context of IoTcommerce, we depicted the related activity system schematically in Fig. 2. Embedded in the socio-economic framework of rules (e.g., legislation), community (e.g., peer customers), and roles (e.g., social demography), the customer interacts with a retailer or manufacturer in different steps of the buying process. As described in the background section, we exemplarily relied on the 9-step buying process of Lemon and Verhoef (2016). In each step of the buying process, the customer (i.e., Person) might use her IoT device (i.e., Tool) in the interaction (i.e., goal-directed actions) with the retailer/ manufacturer (i.e., Object) in order to satisfy her need with a purchase and the subsequent consumption/usage (i.e., goal orientation). Mainly derived from technical features and the socio-economic characteristics of IoT-commerce, the IoT device provides opportunities for action (i.e., affordances) to the customer. Each affordance (e.g., 'electronic transactions') might manifest in one or more steps of the buying process (e.g., 'ordering' and 'payment'). And in each step of the buying process (e.g., 'search'), one or more affordances (e.g., 'natural interaction' and 'automated customer processes') might manifest. These manifestations of affordances along the buying process might then be actualized if the customer performs respective goal-directed actions.

\section{Validation for completeness and parsimony with real-life objects}

We now validate the twelve affordances of IoT-commerce regarding completeness and parsimony. For this purpose, we assess the manifestations of the affordances along the customer buying process. This assessment levers the twelve affordances and a sample of 35 relevant IoT devices that were grouped into five categories such as 'voice assistants' and 'replenishment services'. See Table 1 for definitions of the IoT device categories and exemplary product names. In this section, we show the relationships between all twelve affordances and the nine steps of the buying process. In Table 3, we use a bullet (' $\bullet$ ') to indicate whether an affordance manifests in a step of the buying process. Table 3 shows the aggregated results whereas details can be found in Appendix 1 Table 5.

Each step of the customer buying process comprises six to eleven manifestations of the affordances. Social interactions manifest in every step of the customer buying process, whereas electronic transactions, natural interactions, and automated customer processes lead to a manifestation in eight of nine steps. Online platforms, temporal independence, and spatial independence manifest in seven of nine steps. Location-based services (five of nine steps), information transparency, personalized services, proactive services, and context-aware services (four of nine steps) take effect in around half of all customer buying process steps. As presented in Table 3, all affordances manifest in multiple steps of the customer buying process. This suggests that the overview of IoT-commerce affordances is parsimonious. None of the affordances could be dropped without losing substantive content.

To check for completeness, two authors independently examined 337 IoT devices, filtered those relevant for retail commerce, and grouped them into five categories as described in Table 1 . A check of these IoT devices did not yield any additional affordances not yet covered by Table 2, which was distilled based on extant academic literature. Therefore, we assume our overview of IoT-commerce affordances (Table 2) to be complete as all revealed opportunities to lever IoT devices in the context of retail commerce were already covered. Furthermore, the examination confirmed the manifestation of all affordances in at least four steps along the customer buying process as already observable today.

We see manifestations of affordances that are unique to IoT-commerce (e.g., using voice, haptics, gesture, or other natural interaction to search for products and services), and affordances that became apparent with e-commerce or $\mathrm{m}$ commerce and now continue within IoT-commerce (e.g., perceiving a lowered barrier to pursue the fulfillment of a need) perhaps even intensified due to comfort that comes along with IoT devices. Note that the steps of the buying process and consequently the manifestations of the affordances are not necessarily in the mentioned order, but can vary (e.g., a customer can engage with an organization before the actual consumption, for instance when writing a product review about the ordering process before receiving/using the product). Furthermore, some steps can be skipped (e.g., a customer 
spontaneously considers buying a product without searching for alternatives, directly jumping from 'consideration' to 'choice'). In the following, we provide details on the manifestations and real-life examples.

The steps of the pre-purchase stage (i.e., 'need recognition', 'consideration', and 'search') comprise six to eleven manifestations of affordances in each step. In the step 'need recognition', customers might be guided by personalized advertisements and proactive recommendations for products and services that may even be dependent on the location of the IoT device and/or customer. Customers may also recognize unidentified needs through social interaction with their peers via social networks and the encountered content. With its context-aware sensors, IoT devices offer an additional alternative to recognize the needs of customers. For instance, solutions for smart resource management such as smart thermostats or smart sprinklers collect environmental data like room temperature or weather conditions. With smart algorithms, the IoT device analyzes this sensor data to evaluate whether the room temperature is too cold or the lawn demands watering, without the customer triggering this process of automated need recognition (automated customer process). This is a brief example of the manifestation of IoT affordances in the first step of the customer buying process, namely 'need recognition'. Further exemplifications for the eight following steps can be found in Appendix 2.

Table 4 Components and evaluation of theory

Theory Component (as proposed by Gregor 2006)

Means of representation

Our theory of IoT-commerce is described in words, tables, and pictures. Words are used for detailed explanations enriched by examples. Tables are used to structure the main constructs of our theory, the affordances of IoT-commerce as well as the manifestations of those affordances along the buying process. Schematic pictures illustrate the main constructs within the activity system as a theoretical foundation.

Constructs

Constructs comprise the customer (i.e., Person and goal-oriented actor), the IoT device (i.e., Tool), the retailer/manufacturer (i.e., Object), steps in the customer buying process (i.e., nine steps in three stages), three waves of commerce evolution (i.e., e-commerce, m-commerce, and IoT-commerce), and the generic concept of affordances in context of retail commerce (i.e., opportunities for goal-directed actions).

In particular, we present twelve affordances of IoT-commerce (e.g., natural interaction) and their manifestations along the buying process (e.g., using voice commands in the step of 'search'). The constructs used in our theory are itself theoretically founded in Activity Theory and Affordance Theory.

Statements of relationship

The relationship between the customer, the IoT device, and the retailer/manufacturer is derived from Activity and Affordance Theories and described in detail. Based on this theoretical foundation, we explain the relationship of the twelve affordances with the three waves of retail commerce. We furthermore present relationships between affordances and the steps of the buying process in the sense of manifestations.

Scope

As the majority of the examined literature is composed by European, American, and Asian researchers, our theory shall be applicable in those regions. However, as we expect technological development to continuously spread further, we are convinced that our theory holds true for nearly all geographic regions and social demographics. Importantly, it is restricted to retail commerce and does not cover business-to-business (B2B) commerce.

Evaluation Criterion (as proposed by Weber 2012)

Importance

Our theory provides insights into the changing nature of retail commerce driven by the diffusion of the IoT. Impacting customer behavior, creating technological opportunities, and potentially facilitating innovative business models, IoT-commerce should be considered as an important domain for both researchers and practitioners. Our theory conceptualizes IoT-commerce and identifies its affordances. As such, it is a basis for further research in this area of growing practical relevance.

Novelty

Driven by the emerging phenomenon of IoT, our theory about IoT-commerce provides insights into the evolution of retail commerce that no researcher has examined in detail yet.

Parsimony

Our theory comprises a conceivable small number of constructs and omits aspects not directly relevant for the explanatory power of the theory (such as legislative aspects). Affordances and their manifestations are presented compactly.

Level Our research is framed as a middle-range (meso) theory avoiding 'narrow empiricism' and 'over-generalization'.

Falsifiability

With the transformation of affordances into manifestations along the buying process, our theory can be tested if all affordances actually manifest and potentially be falsified if different observations are made. 


\section{Discussion}

From a theoretical perspective, we examined extant literature and research streams in the field of retail commerce and structured it along three waves, namely e-commerce, $\mathrm{m}$-commerce, and IoT-commerce. We also investigated the literature of IoT that so far primarily focused on technical and business-related but not on customer-focused aspects. Bringing together both domains, we shed light and extend the body of knowledge at the intersection of retail commerce and IoT that we call IoT-commerce. We investigate this field with a customer-centric IS perspective. Conceptualizing IoT-commerce is the first theoretical contribution of this paper. In particular, we analyzed the influence and opportunities of IoT devices in the customer buying process. This is especially relevant due to its fundamental impact on both customers and companies. In this, we identified twelve affordances of IoT-commerce from a customer perspective. The identification, conceptualization, and linkage of these affordances to the customer buying process is this paper's second theoretical contribution.

Nine of the twelve affordances of IoT-commerce are already known from e-commerce and m-commerce. It is important to note that they carry on in IoT-commerce. Within IoT-commerce, they might be present or might be actualized more frequently than before. However, these nine affordances are not qualitatively new and, thus, less disruptive than the new affordances. Three affordances of IoT-commerce - namely context-aware services, natural interactions, and automated customer processes - are qualitatively new as compared to prior forms of IT-enabled retail commerce. As our analysis highlights, these three new affordances jointly affect each step in the customer buying process. Current real-life examples of IoT devices already demonstrate how these affordances manifest along the buying process. However, we are only at the beginning of the IoT era. On the one hand, IoT devices are about to spread into private homes and lives transforming online shopping at a fast pace. On the other hand, organizations constantly enlarge functionalities of IoT devices in order to gather more data of individual users, provide more convenience and service, and better predict individual user behavior. As our affordances and their respective manifestations show, IoT has the potential to innovate the customer buying process we currently know from e-commerce and $\mathrm{m}$-commerce. Consequently, we are convinced that IoTcommerce is a highly relevant research topic that is gaining considerably in importance within the next years. With our research, we contribute to its theoretical foundation and offer insight into IoT-commerce from a customer's point of view.

Our work itself is theoretically founded in Activity Theory and Affordance Theory. A combination of both was a suitable tool to develop our theory of IoT-commerce based on extant theory in the areas of e-commerce, m-commerce, and IoT. In Table 4, we briefly summarize our theory components and evaluate them. Gregor (2006) presented a widely used typology of theories in IS research (about 3000 citations according to Google Scholar). Based on four primary goals of theory (analysis and description, explanation, prediction, prescription) she identified different types of theories and components of such theories (Table 3 of Gregor 2006). Within these components, four components are common to all theories: means of representation, constructs, statements of relationship, and scope. In Table 4, we use these four mandatory components of theories in IS as a structure to present our theory of IoTcommerce as we believe that following this structure adds clarity to the presentation of our contribution. To summarize the evaluation of our theory, we refer to the criteria suggested by Weber (2012). Weber presents a detailed framework and criteria for evaluating theories in IS research. He presents criteria relating to the different parts of a theory individually and to the theory as a whole. For brevity of presentation, we restrict the discussion in Table 4 to the five criteria for the theory as a whole (importance, novelty, parsimony, level, falsifiability) as these appear to us more insightful for the theory at hand than the criteria for individual parts.

From a practical point of view, our paper on the opportunities of IoT devices serves as a tool for customers as well as companies. For retail customers, it initiates critical reflections about the use of IoT devices in the buying process. We provide them with insights on how IoT contributes to their customer experience, for instance, that customer activity is less necessary and that the barrier to pursue the fulfillment of a need decreases significantly. Furthermore, customers comprehend better when IoT decreases their sovereignty and self-determination, initiating reflections about the trend towards automated decision-making with a high volume of data collection. For organizations, we provide a theoretical foundation and structure to analyze their products and services in order to identify opportunities (e.g., enhance customer experience, increase customer loyalty, create lock-in effects) and risks (e.g., speed of IoT usage by competitors, slow adaption to changing customer behavior). For organizations, it is important to analyze the impact of IoT-commerce on their business model and initiate strategies to minimize risks and increase opportunities. For instance, IoT bears the opportunity for manufacturers to sell directly to the customer, and therefore establish a direct customer relationship by omitting a retailer. In 
contrast, retailers risk to lose direct customer contact in case manufactures directly sell to end customers. Those aspects must be assessed and considered in suitable business models. Overall, we found the most interesting manifestations of affordances newly arising from IoT devices in the pre- and post-purchase stages, whereas the purchase stage is primarily characterized by a reinforcement of the affordances that already emerged with e-commerce and m-commerce as well as natural interaction of the customer with the device and automation of choice, ordering, and payment.

As any research endeavor, our paper is beset with limitations that stimulate further research. First, we do not compile a full set of all existing (or even future) IoT devices. Although we drew on a broad sample from three publications with 337 devices in total, filtered to 35 relevant examples, and generalized into five categories, innovative IoT devices will emerge and may afford new actions for future retail customers. Of course, we cannot assure that we covered all kinds of devices that might come up. Further research could consider upcoming IoT devices in the next years and, if necessary, revise our IoT device categories, redo the validation for completeness and parsimony, and extend our overview of IoTcommerce affordances if completely new functions emerged. Furthermore, our paper focuses on the retail commerce context (B2C). Given the numerous usages of IoT devices in the B2B context, further research should check the applicability of our affordances in B2B commerce.

Future research might want to go beyond the mitigation of the above limitations and investigate into follow-up questions such as: Which differences can be observed between real and perceived affordances (e.g., role of tech-savviness or cultural background of customers)? How do customers accept the new technology-driven phenomenon of IoT-commerce (e.g., are these conscious perception and actualization processes)? How do the affordances change customer purchasing behavior over time and compared to e-commerce and m-commerce (e.g. changes in brand loyalty, frequency of purchases, or in the relative weight of different purchasing criteria)? Are there any negative side effects for customers associated with IoTcommerce (e.g., self-creation of lock-in effects)? How can established and emerging companies lever the opportunities of IoT-commerce to offer and monetize additional customer value (e.g., how to integrate IoT-commerce into multi- or omnichannel customer interaction)? To which biases (e.g., information bias) and nudges (e.g., recommendations) are customers exposed in IoT-commerce and how can businesses lever IoT-spawned technology to overcome or utilize these biases and nudges? Other work beyond IoT-commerce affordances might want to focus on the role of legislation, the influence of data privacy, a rigorously developed taxonomy of IoT devices in retail commerce, emerging business models, or an ethical perspective (e.g., potential moral issues affiliated with functionality such as automated decisionmaking).

\section{Conclusion}

This work was motivated by analyzing IoT in the context of commerce in a customer-centric manner. Through an affordance lens, we answered our research question which opportunities IoT devices provide to retail commerce customers. Theoretically founded in Activity Theory and Affordance Theory, we develop our theory of IoT-commerce as a third wave in the evolution of retail commerce following e-commerce and m-commerce. We identified 49 relevant articles in a structured literature search in leading IS journals, commerce journals, marketing journals, and the domain of computer science and therefrom extracted twelve affordances. Seven affordances emerged with e-commerce, two with $\mathrm{m}$ commerce, and three additional affordances originate from IoT-commerce. To evaluate our theory and to demonstrate its applicability, we derived manifestations of the twelve affordances along with the nine steps in three stages of the customer buying process. We further extracted 35 relevant IoT devices out of a sample with 337 real-life IoT devices, grouped them into five categories, and levered them to confirm completeness and parsimony. Overall, our paper helps understand the influence of the IoT phenomenon on retail commerce in a customer-centric manner.

As IoT-commerce is still in its infancy, its future holds tremendous potential. Due to the increasing proliferation of IoT devices, its importance for retail commerce may continuously rise. Similar to the trend of customers preferring mobile devices before desktop PCs for ordering online, IoT devices might become a vital - or even the most vital - channel for retail commerce in the near future. Hence, detailed analysis and understanding of the IoT-commerce phenomenon and its consequences for both customers and companies is of utmost importance and represents the crucial basis for further goal-directed action. Academic research might, therefore, want to keep up with this fast-evolving phenomenon and answer related questions such as those raised in the previous section.

Funding Information Open Access funding provided by Projekt DEAL. 


\section{Appendix 1: Manifestations of IoT-commerce affordances along the customer buying process}

Table 5 Manifestations of IoT-commerce affordances along the customer buying process

\begin{tabular}{|c|c|}
\hline Step & IoT-commerce affordance \\
\hline need recognition & $\begin{array}{l}\text { - Social interactions: Recognizing an unidentified need through social interaction with peers } \\
\text { - Personalized services: Let oneself being guided by personalized product and service advertisement } \\
\text { - Proactive services: Let oneself being guided by proactive product and service recommendations } \\
\text { - Location-based services: Let oneself being guided by location-based advertisements and recommendations } \\
\text { - Context-aware services: Recognizing needs through environmental sensor data } \\
\text { - Automated customer process: Automated need recognition based on customer, peer, and public data }\end{array}$ \\
\hline consideration & $\begin{array}{l}\text { - Electronic transactions: Perceiving a lowered barrier to pursue the fulfillment of the need } \\
\text { - Temporal independence: Perceiving a lowered barrier to pursue the fulfillment of the need } \\
\text { - Information transparency: Perceiving a lowered barrier to pursue the fulfillment of the need } \\
\text { - Social interactions: Considering social knowledge and experiences of peers } \\
\text { - Personalized services: Let oneself being guided by personalized product and service advertisement } \\
\text { - Proactive services: Let oneself being guided by proactive recommendations } \\
\text { - Spatial independence: Perceiving a lowered barrier to pursue the fulfillment of the need } \\
\text { - Location-based services: Let oneself being guided by location-based advertisements and recommendations } \\
\text { - Natural interactions: Perceiving a lowered barrier to pursue the fulfillment of the need } \\
\text { - Automated customer process: Automated decision in the background whether to pursue the fulfillment of the need }\end{array}$ \\
\hline search & $\begin{array}{l}\text { - Electronic transactions: Searching a broad range of digital and non-digital products and services online } \\
\text { - Temporal independence: Searching products and services at any time } \\
\text { - Online platforms: Searching products and services across manufacturers on central marketplaces } \\
\text { - Information transparency: Getting access to a broad range of information about products, services, manufacturers, and other } \\
\text { background information } \\
\text { - Social interactions: Considering social knowledge and experiences of peers } \\
\text { - Personalized services: Let oneself being guided by personalized search results } \\
\text { - Proactive services: Let oneself be guided by recommendations of certain products and services instead of search } \\
\text { - Spatial independence: Searching products and services from everywhere } \\
\text { - Location-based services: Let oneself being guided by search results based on location } \\
\text { - Natural interactions: Using voice, haptics, gesture, or other natural interaction to search for products and services } \\
\text { - Automated customer process: Replacing customer's search by automated search in the background based on customer prefere }\end{array}$ \\
\hline
\end{tabular}

Purchase stage

$\begin{array}{ll}\text { Step } & \text { IoT-commerce affordance } \\ \text { choice } & \text { - Electronic transactions: Choosing among relevant products and services online } \\ \text { - Online platforms: Accessing information about products and services via central marketplaces } \\ \text { - Information transparency: Data-based comparing of products and services } \\ \text { - Social interactions: Accessing user-generated content about products and services } \\ \text { - Natural interactions: Using voice, haptics, gesture, or other natural interaction to choose between products and services } \\ \text { - Automated customer process: Automated decision on product or service in the background based on customer preferences } \\ \text { - Electronic transactions: Ordering products and services remotely without the need to visit a brick and mortar store } \\ \text { - Temporal independence: Ordering products and services at any time } \\ \text { - Online platforms: Bundled ordering from a multitude of sellers via central marketplaces } \\ \text { - Social interactions: Sharing the moment of purchase and the whole shopping experience via social networks } \\ \text { - Spatial independence: Ordering products and services from everywhere } \\ \text { - Natural interactions: Using voice, haptics, gesture, or other natural interaction to order products and services } \\ \text { - Automated customer process: Replacing customer's ordering by automated ordering in the background } \\ \text { - Electronic transactions: Paying electronically with digital and non-digital currencies via the Internet } \\ \text { - Temporal independence: Paying orders at any time } \\ \text { - Online platforms: Bundled paying to a multitude of sellers via a marketplace } \\ \text { - Social interactions: Paying via P2P payment solutions } \\ \text { - Natural interactions: Using voice, haptics, gesture, or other natural interaction for payment } \\ \text { - Automated customer process: Replacing customer's payment by automated payment in the background }\end{array}$


Table 5 (continued)

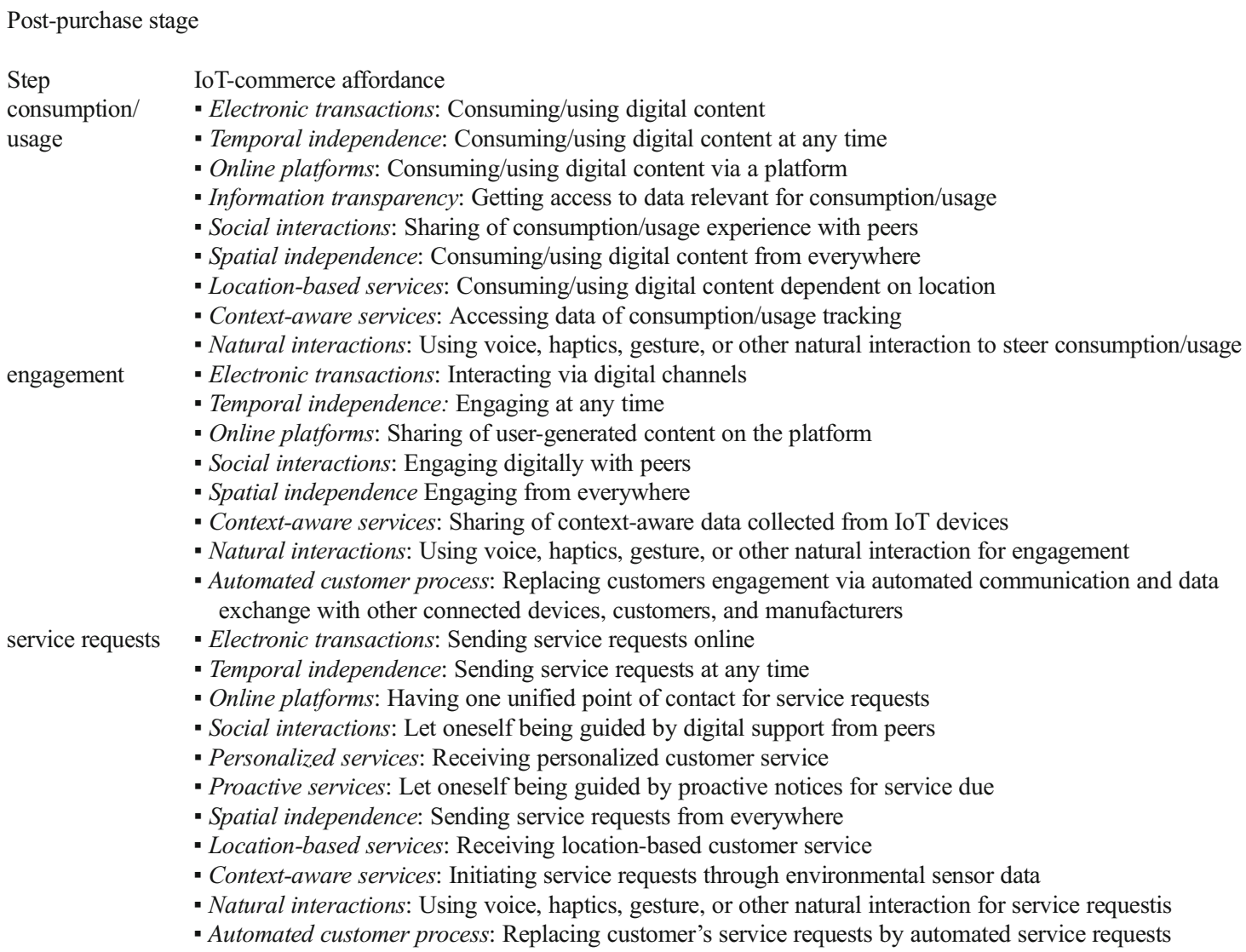

\section{Appendix 2: Textual explanation of manifestations of loT-commerce affordances along the customer buying process}

This Appendix 2 provides exemplifications for the manifestations of affordances along the buying process. The first step need recognition of the pre-purchase stage is explained in the section "Validation for completeness and parsimony with real-life objects" section. In the following, the remaining eight steps of the customer buying process are covered.

In the step 'consideration', half of all affordances lead to lower perceived barriers to fulfill the recognized need due to the convenience of electronic transactions that customers may conduct temporally and spatially independent. Easy access to relevant information (information transparency) and natural interactions such as voice commands to voice assistants, haptic touches or clicks on a button of a replenishment service also contribute to a perceived lower barrier to fulfill one's need due to the knowledge that fulfillment with IoT devices is convenient and easy. Beyond the possibility that customers' consideration to pursuing the purchase of a product or service is guided by personalized advertisements and proactive recommendations that may even be dependent on the location of the
IoT device and/or customer, social interaction may also reveal experiences of peers that influence the consideration whether and how to fulfill a need. Due to customer process automation with algorithms, IoT devices might also decide automatically whether to proceed in the buying process, without further intervention of the customer. For instance, smart energy management solutions already decide on their own whether a room shall be heated, or a lawn shall be watered or the washing machine decides automatically whether to reorder detergent.

The 'consideration' step is followed by the 'search' step. Customers are able to search a broad range of products and services online (electronic transactions) and across manufacturers on online marketplaces (online platforms) independent from temporal and spatial restrictions. Search results can be tailored to the location and personalized to the preferences of an individual customer. Within this search, customers obtain easy access to information about products and services, its manufacturers, and other details relevant to the search (information transparency). Furthermore, social knowledge and experiences (social interaction), for instance, product ratings on a platform or social media posts from peers about the product, may guide the customer's search process. Proactive recommendations may influence and shorten the search process 
whereas smart algorithms of IoT devices may fully automate the search for customers (automated customer process). From an interaction point of view, voice assistants allow to conveniently search for products via voice commands, and replenishment services (e.g., smart fridges) via embedded touch displays (natural interaction).

The steps of the purchase stage (i.e., 'choice', 'ordering', and 'payment') comprise six to seven manifestations of affordances in each step. As known from e-commerce and $\mathrm{m}$-commerce, choice, ordering, and payment in IoTcommerce can be conducted online via electronic transactions, independent from temporal and spatial restrictions, and via online platforms. Information transparency allows easy comparison of products and services that are enriched with social interaction such as the access to and the sharing of user-generated content in the steps 'choice' and 'ordering' or even the payment with a P2P payment solution such as Bitcoin. The main differences compared to the prior waves of e-commerce and m-commerce are driven by the IoT-commerce affordance natural interaction and automated customer processes. Customers can use natural interaction to choose between products and services, order, and pay them online. Voice assistants allow to execute commands via voice; smart resource management and replenishment services (e.g., smart fridges) offer displays for haptic touches; replenishment services such as the Amazon Dash Button allow to choose, order, and pay products online via a simplified interface - by pressing a button. In contrast, gesture control is not yet present in widespread IoT devices. Smart algorithms add intelligence to IoT devices and their connected service offerings (automated customer process). This intelligence enables IoT devices to choose, order, and pay products and services automatically based, for instance, on customer's preferences. This automation is making any direct intervention of the customer obsolete, as for example fully selfsufficient replenishment services for washing detergent. Furthermore, solutions for smart resource management, however, already optimize the consumption of electricity, water, or other resources automatically without the customer's involvement and therefore influence directly the quantity and time of resource consumption.

The steps of the post-purchase stage (i.e., 'consumption/ usage', 'interaction', and 'service request') are located after the actual purchase stage and comprise eight to eleven affordances in each step. In the step of 'consumption/ usage', digital content (electronic transactions), for instance, a series on Netflix and music on Spotify, can be consumed via a platform (online platforms) at any time (temporal independence). Whenever you would like to listen to music on Spotify or watch a series on Netflix, you can log in to the platforms via any device (e.g., mobile phone or voice assistant) and instantly start to consume the product such as listening to a song. Due to the diversity of devices and the inherent nature of digital content, it can be consumed spatially independent. For instance, a song can be listened to via your Spotify account on your mobile phone during a picnic in the park or seamlessly in all rooms with connected voice assistants. Some providers offer location-based services during consumption/usage. For instance, a car-sharing vehicle displays car-sharing parking areas nearby or services that might initiate new buying processes such as vouchers for nearby shops. Furthermore, customers are able to share data, opinions, and experiences about consumption/usage of a product or service easily with peers, for instance via social networks (social interactions). It might be opinions about digital content, but also about non-digital products and services. Those written product reviews on platforms, shared moments of consumption/usage on Instagram and Facebook, and product ratings on the manufacturer's website become part of the user-generated content that might influence other peers in their buying process (e.g., within 'choice'). Furthermore, customers can get easy access to data relevant for consumption/usage of the product or service (information transparency). For instance, the name of the current song is displayed on the screen of the IoT device or the voice assistant is able to tell the ingredients of the bought food during cooking. IoT devices may also save historical data about consumption/usage, for instance, collected via sensors (context-aware services). Customers can get access to this background data about their consumption via a mobile app (e.g., energy consumption history provided by the smart resource management system). To steer the consumption of digital content, the customer can use natural interactions such as her voice. For instance, she can request the voice assistant to play a certain song, without having to search manually for it on the smartphone.

In the step of 'engagement', customers can interact digitally (electronic transactions), at any time (temporal independence), and from everywhere (spatial independence) in order to engage with other customers (social interaction) or organizations, for instance, to provide feedback about products on platforms (online platforms), engaging in co-creation of a new product, or engaging in a digital customer community. Furthermore, customers can share and compare data collected by IoT devices via sensors with organizations and peer customers (context-aware services). Customers might want to compare their reduction of energy consumption since the purchase of a smart energy management system with historic consumption data of other customers. Active engagement of customers is facilitated via comfortable and easy interaction with connected devices in the living space of the customer. For instance, voice assistants (natural interactions) are integrated into customers' daily life - who can quickly leave a product rating of washing powder while doing the laundry. Smart algorithms replace individual customer actions via automated communication and data exchange among other connected devices, customers, and manufacturers (automated customer 
processes). For instance, smart thermostats already send data about energy consumption to the provider; nowadays mostly after allowed by the customer.

'Service requests' are sent online (electronic transactions) at any time (temporal independence) and from everywhere (spatial independence) with natural interactions as for instance voice. Due to online platforms, customers are offered one unified point of contact for sending service requests (online platforms): After logging into their account on a platform, customers see their previous service requests, can contact the provider and (re-)schedule appointments, without the necessity of using a second device, as for example a phone to call the service provider. In communities, customers receive support from their peers in problem solution (social interaction). Due to data about customer preferences, consumption history, sensor data, and other data available to the service provider, personalized and location-based services can be offered. Furthermore, customers receive notifications about service requests proactively (proactive services). Due to smart algorithms, service requests are even sent automatically without the involvement of the customer (automated customer process). An automated service request might be triggered through tracking data of the IoT device accessible to the provider, as for example a certain distance covered by the vehicle after which service is recommended, or sensor data (context-aware services), as for example a car automatically informing its sharing company in case of a breakdown.

Open Access This article is licensed under a Creative Commons Attribution 4.0 International License, which permits use, sharing, adaptation, distribution and reproduction in any medium or format, as long as you give appropriate credit to the original author(s) and the source, provide a link to the Creative Commons licence, and indicate if changes were made. The images or other third party material in this article are included in the article's Creative Commons licence, unless indicated otherwise in a credit line to the material. If material is not included in the article's Creative Commons licence and your intended use is not permitted by statutory regulation or exceeds the permitted use, you will need to obtain permission directly from the copyright holder. To view a copy of this licence, visit http://creativecommons.org/licenses/by/4.0/.

\section{References}

Adolphs, C., \& Winkelmann, A. (2010). Personalization research: A rigorous literature review on personalization in e-commerce (20002008). Journal of Electronic Commerce Research, 11(4), 326-341.

AIS (2018). Senior Scholars' Basket of Journals. Retrieved November 20, 2018, from https://aisnet.org/page/SeniorScholarBasket.

Akter, S., \& Wamba, S. F. (2016). Big data analytics in e-commerce: A systematic review and agenda for future research. Electronic Markets, 26(2), 173-194.

Aldridge, D. (1998). Purchasing on the net: The new opportunities for electronic commerce. Electronic Markets, 8(1), 34-37.

Allen, D. K., Brown, A., Karanasios, S., \& Norman, A. (2013). How should technology-mediated organizational change be explained?
A comparison of the contributions of critical realism and activity theory. MIS Quarterly, 37(3), 835-854.

Al-Obeidat, F., Spencer, B., \& Kafeza, E. (2018). The opinion management framework: Identifying and addressing customer concerns extracted from online product reviews. Electronic Commerce Research and Applications, 27, 52-64.

Alt, R., \& Klein, S. (2011). Twenty years of electronic markets research: Looking backwards towards the future. Electronic Markets, 21(1), $41-51$.

Amazon (2018a). Amazon Echo. Retrieved November 20, 2018, from https://www.amazon.com/echo.

Amazon (2018b). Dash Replenishment Service. Retrieved December 20, 2018, from https://developer.amazon.com/de/dash-replenishmentservice.

Baek, H., Ahn, J., \& Choi, Y. (2012). Helpfulness of online consumer reviews: Readers' objectives and review cues. International Journal of Electronic Commerce, 17(2), 99-126.

Bærentsen, K. B., \& Trettvik, J. (2002). An activity theory approach to affordance. In Proceedings of the 2nd Nordic conference on Humancomputer interaction (NordiCHI 2002) (pp. 51-60).

Baethge, C., Klier, J., \& Klier, M. (2016). Social commerce: State-of-theart and future research directions. Electronic Markets, 26(3), 269290.

Barbosa, J. L. V. (2015). Ubiquitous computing: Applications and research opportunities. In Proceedings of the IEEE International Conference on Computational Intelligence and Computing Research (ICCIC 2015) .

Beaudry, A., \& Carillo, K. D. (2006). The customer-centered B2C literature through the lens of activity theory: A review and research agenda. Communications of the Association for Information Systems, 17(1), 428-503.

Benbunan-Fich, R. (2019). An affordance lens for wearable information systems. European Journal of Information Systems, 28(3), 256-271.

Bhajantri, L. B., Nalini, N., \& Rathod, S. H. (2015). Collaborative filtering technique based recommendation in ubiquitous commerce. In Proceedings of the International Conference on Applied and Theoretical Computing and Communication Technology (iCATccT 2015) (pp. 573-578).

Borgia, E. (2014). The internet of things vision: Key features, applications and open issues. Computer Communications, 54, 1-31.

Brandt, R., Püschel, L., Röglinger, M., \& Schlott, H. (2017). Unravelling the internet of things: A multi-layer taxonomy and archetypes of smart things. Working Paper of the FIM Research Center. Retrieved February 18, 2018.

Brynjolfsson, E., \& Smith, M. D. (2000). Frictionless commerce? A comparison of internet and conventional retailers. Management Science, 46(4), 563-585.

Butler, P., \& Peppard, J. (1998). Consumer purchasing on the internet: Processes and prospects. European Management Journal, 16(5), $600-610$

Cambridge Dictionary (2019a). Definition of "product". Retrieved October 02, 2019, from https://dictionary.cambridge.org/de/ worterbuch/englisch/product.

Cambridge Dictionary (2019b). Definition of "service". Retrieved October 02, 2019, from https://dictionary.cambridge.org/de/ worterbuch/englisch/service.

Chaudhury, A., Mallick, D. N., \& Rao, H. R. (2001). Web channels in ecommerce. Communications of the ACM, 44(1), 99-104.

Chua, C., Khoo, H., Straub, D., Kadiyala, S., \& Kuechler, D. (2005). The evolution of e-commerce research: A stakeholder perspective. Journal of Electronic Commerce Research, 6(4), 262-280.

Chunxia, Q., Zhenzhong, Z., \& Litao, Z. (2010). A shopping model in ubiquitous media environment. In Proceedings of the International Forum on Information Technology and Applications (IFITA 2010) (pp. 319-322). 
Clarke, I. I. (2008). Emerging value propositions for m-commerce. Journal of Business Strategies, 25(2), 41-57.

Coughlan, T., Brown, M., Mortier, R., Houghton, R. J., Goulden, M., \& Lawson, G. (2012). Exploring acceptance and consequences of the internet of things in the home. In Proceedings of the IEEE International Conference on Green Computing and Communications (GreenCom 2012) (pp. 148-155).

Cui, Y., Mou, J., \& Liu, Y. (2018). Knowledge mapping of social commerce research: A visual analysis using CiteSpace. Electronic Commerce Research, 18(4), 837-868.

Cunningham, L. F., Gerlach, J. H., Harper, M. D., \& Young, C. E. (2005). Perceived risk and the consumer buying process: Internet airline reservations. International Journal of Service Industry Management, 16(4), 357-372.

Deloitte (2016). Switch on to the connected home: The Deloitte Consumer Review. Retrieved December 20, 2018, from https:// www2.deloitte.com/content/dam/Deloitte/uk/Documents/ consumer-business/deloitte-uk-consumer-review-16.pdf.

Engel, J. F., Blackwell, R. D., \& Miniard, P. W. (1995). Consumer behavior (8th ed.). Fort Worth, Texas, USA: Dryden.

Engeström, Y. (1987). Learning by expanding: An activity-theoretical approach to developmental research. Helsinki, Finland: OrientaKonsultit Oy.

Evans, M. (2017, January 24). 5 Ways the internet of things will influence commerce. Forbes. Retrieved January 30, 2019, from https://www. forbes.com/sites/michelleevans1/2017/01/24/5-ways-the-internetof-things-will-influence-commerce.

Evans, M. (2018, May 31). Iot will have the most impact on business in the next five years, survey says. Forbes. Retrieved January 30, 2019, from https://www.forbes.com/sites/michelleevans1/2018/05/31/iotwill-have-the-most-impact-on-business-in-the-next-five-yearssurvey-says.

Farhad, M. (2018, October). 10. New York Times: A future where everything becomes a computer is as creepy as you feared Retrieved January 19, 2019, from https://www.nytimes.com/2018/10/10/ technology/future-internet-of-things.html.

Fleisch, E., Sarma, S., \& Thiesse, F. (2009). Preface to the focus theme section: 'Internet of things'. Electronic Markets, 19(2-3), 99-102.

Fox, P., Rezania, D., Wareham, J., \& Christiaanse, E. (2006). Will mobiles dream of electric sheep? Expectations of the new generation of mobile users: Misfits with practice and research. In Proceedings of the International Conference on Mobile Business (ICMB 2006). Copenhagen.

Frambach, R. T., Roest, H. C. A., \& Krishnan, T. V. (2007). The impact of consumer internet experience on channel preference and usage intentions across the different stages of the buying process. Journal of Interactive Marketing, 21(2), 26-41.

Fu, D., Hong, Y., Wang, K., \& Fan, W. (2018). Effects of membership tier on user content generation behaviors: Evidence from online reviews. Electronic Commerce Research, 18(3), 457-483.

Gaskin, J., Berente, N., Lyytinen, K., \& Yoo, Y. (2014). Toward generalizable sociomaterial inquiry: A computational approach for zooming in and out of sociomaterial routines. MIS Quarterly, 38(3), 849-871.

Gaur, A., Scotney, B., Parr, G., \& McClean, S. (2015). Smart city architecture and its applications based on iot. Procedia Computer Science, 52, 1089-1094.

Gaver, W. W. (1991). Technology affordances. In Proceedings of the SIGCHI Conference on Human Factors in Computing Systems (CHI 1991) (pp. 79-84).

Gaver, W. W. (1992). The affordances of media spaces for collaboration. In Proceedings of the ACM conference on Computer-supported cooperative work (CSCW 1992) (pp. 17-24).

Gefen, D., Karahanna, E., \& Straub, D. (2003). Trust and TAM in online shopping: An integrated model. MIS Quarterly, 27(1), 51-90.
Gengatharen, D. E., \& Standing, C. (2005). A framework to assess the factors affecting success or failure of the implementation of government-supported regional e-marketplaces for SMEs. European Journal of Information Systems, 14(4), 417-433.

Gibson, J. J. (1979). The ecological approach to visual perception. Boston: Houghton Mifflin.

Grandon, E. E., \& Pearson, J. M. (2004). Electronic commerce adoption: An empirical study of small and medium US businesses. Information \& Management, 42(1), 197-216.

Gregor, S. (2006). The nature of theory in information systems. MIS Quarterly, 30(3), 611-642.

Groenfeldt, T. (2016, January 06). Touchscreen On The Fridge: Door To Order Groceries, Watch Football. Forbes. Retrieved January 30, 2019, from https://www.forbes.com/sites/tomgroenfeldt/2016/01/ 06/touchscreen-on-the-fridge-door-to-order-groceries-watchfootball.

Groß, M. (2015). Mobile shopping: A classification framework and literature review. International Journal of Retail \& Distribution Management, 43(3), 221-241.

Guttman, R., Moukas, A., \& Maes, P. (1999). Agents as mediators in electronic commerce. In M. Klusch (Ed.), Intelligent information agents. Agent-based information discovery and management on the internet (pp. 131-152). Berlin, New York: Springer.

Hartson, H. R. (2003). Cognitive, physical, sensory, and functional affordances in interaction design. Behavior \& Information Technology, 22(5), 315-338.

Hasan, H., \& Kazlauskas, A. (2014). Activity theory: Who is doing what, why and how. In H. Hasan (Ed.), Being practical with theory. A window into business research (pp. 9-14). THEORI: Wollongong, Australia.

Heatman, A. (2018). FridgeCam is the Internet of Things device that will actualy improve your life. Retrieved January 19, 2018, from https:// www.standard.co.uk/tech/fridgecam-internet-of-things-food-wastea3891031.html.

Ho, Y.-C., Wu, J., \& Tan, Y. (2017). Disconfirmation effect on online rating behavior: A structural model. Information Systems Research, 28(3), 626-642.

Hoffman, D. L., \& Novak, T. P. (2018). Consumer and object experience in the internet of things: An assemblage theory approach. Journal of Consumer Research, 44(6), 1178-1204.

Hollocks, B. W. (2001). Book review: Handbook on electronic commerce. European Journal of Information Systems, 10(1), 69.

Howard, J. A., \& Sheth, J. N. (1969). The theory of buyer behavior. The Wiley marketing series. New York: Wiley.

Huang, Z., \& Benyoucef, M. (2013). From e-commerce to social commerce: A close look at design features. Electronic Commerce Research and Applications, 12(4), 246-259.

Huber, R., Püschel, L., \& Röglinger, M. (2017). Iot-enabled smart service systems: Identification of actors and interaction types. Working Paper of the FIM Research Center. Retrieved February 18, 2018.

Jing, N., Jiang, T., Du, J., \& Sugumaran, V. (2018). Personalized recommendation based on customer preference mining and sentiment assessment from a Chinese e-commerce website. Electronic Commerce Research, 18(1), 159-179.

Johnston, R. B., \& Gregor, S. (2000). A theory of industry-level activity for understanding the adoption of interorganizational systems. European Journal of Information Systems, 9(4), 243-251.

Junglas, I., \& Watson, R. (2003). U-commerce: A conceptual extension of e-commerce and m-commerce. In Proceedings of the International Conference on Information Systems (ICIS 2003) (Article 55).

Kaptelinin, V. (2005). Activity theory. In Encyclopaedia of human computer interaction. Retrieved November 20, 2018, from https://www. interaction-design.org/literature/book/the-encyclopedia-of-humancomputer-interaction-2nd-ed/activity-theory.

Kaptelinin, V., \& Nardi, B. (2012). Affordances in HCI: Toward a mediated action perspective. In Proceedings of the SIGCHI Conference 
on Human Factors in Computing Systems (CHI 2012) (pp. 967976).

Karanasios, S., \& Allen, D. K. (2014). Mobile technology in mobile work: Contradictions and congruencies in activity systems. European Journal of Information Systems, 23(5), 529-542.

Kees, A., Oberländer, A. M., Röglinger, M., \& Rosemann, M. (2015). Understanding the internet of things: A conceptualisation of business-to-thing (b2t) interactions. In Proceedings of the 23th European Conference on Information Systems (ECIS 2015) (article 92).

Klopping, I. M., \& McKinney, E. (2004). Extending the technology acceptance model and the task-technology fit model to consumer Ecommerce. Information Technology, Learning, and Performance Journal, 22(1), 35-47.

Kocas, C. (2002). Evolution of prices in electronic markets under diffusion of price-comparison shopping. Journal of Management Information Systems, 19(3), 99-119.

Konjengbam, A., Dewangan, N., Kumar, N., \& Singh, M. (2018). Aspect ontology based review exploration. Electronic Commerce Research and Applications, 30, 62-71.

Koverman, C. (2016). Next-generation connected support in the age of iot: It's time to get proactive about customer support. IEEE Consumer Electronics Magazine, 5(1), 69-73. Retrieved September 18, 2019.

Kozinets, R. V. (2019). Consuming Technocultures: An extended JCR Curation. Journal of Consumer Research, 46(3), 620-627.

Kraemer, K. L., Dedrick, J., \& Yamashiro, S. (2000). Refining and extending the business model with information technology: Dell Computer corporation. The Information Society, 16(1), 5-21.

Kurkovsky, S. (2005). Using principles of pervasive computing to design m-commerce applications. In Proceedings of the International Conference on Information Technology: Coding and Computing (ITCC 2005)

Laudon, K. C., \& Traver, C. G. (2018). E-commerce: Business, technology, society (13th ed.). Boston: Pearson.

Lee, H. G., \& Lee, R. M. (1993). Intelligent electronic trading for commodity exchanges. Electronic Markets, 9-10, 5-6.

Lee, I., \& Lee, K. (2015). The internet of things (iot): Applications, investments, and challenges for enterprises. Business Horizons, $58(4), 431-440$.

Lee, S. M., Hwang, T., \& Lee, D. H. (2011). Evolution of research areas, themes, and methods in electronic commerce. Journal of Organizational Computing and Electronic Commerce, 21(3), 177201.

Lee, Y. E., \& Benbasat, I. (2004). A framework for the study of customer interface design for mobile commerce. International Journal of Electronic Commerce, 8(3), 79-102.

Lehrer, C., Wieneke, A., Vom Brocke, J., Jung, R., \& Seidel, S. (2018). How big data analytics enables service innovation: Materiality, affordance, and the individualization of service. Journal of Management Information Systems, 35(2), 424-460.

Lemon, K. N., \& Verhoef, P. C. (2016). Understanding customer experience throughout the customer journey. Journal of Marketing, 80(6), 69-96.

Leonardi, P. M. (2011). When flexible routines meet flexible technologies: Affordance, constraint, and the imbrication of human and material agencies. MIS Quarterly, 35(1), 147-167.

Leong, C., Pan, S. L., Newell, S., \& Cui, L. (2016). The emergence of self-organizing e-commerce ecosystems in remote villages of China: A tale of digital empowerment for rural development. MIS Quarterly, 40(2), 475-484.

Leont'ev, A. N. (1978). Activity, consciousness, and personality. Englewood Cliffs, NJ: Prentice-Hall.

Levina, O., \& Vilnai-Yavetz, I. (2015). E-visibility maturity model: A tool for assessment and comparison of individual firms and sets of firms in e-business. Electronic Commerce Research and Applications, 14(6), 480-498.

Li, S., \& Karahanna, E. (2015). Online recommendation systems in a b2c e-commerce context: A review and future directions. Journal of the Association for Information Systems, 16(2), 72-107.

Li, X., \& Hitt, L. M. (2008). Self-selection and information role of online product reviews. Information Systems Research, 19(4), 456-474.

Li, X., Xu, G., \& Li, L. (2008). Rfid based smart home architecture for improving lives. In Proceedings of the 2nd IEEE International Workshop on Anti-counterfeiting, Security, Identification (ASID 2008)

Liang, T.-P., Ho, Y.-T., Li, Y.-W., \& Turban, E. (2011). What drives social commerce: The role of social support and relationship quality. International Journal of Electronic Commerce, 16(2), 69-90.

Liu, Q., Huang, S., \& Zhang, L. (2016). The influence of information cascades on online purchase behaviors of search and experience products. Electronic Commerce Research, 16(4), 553-580.

Lynch, J. G., \& Ariely, D. (2000). Wine online: Search costs affect competition on price, quality, and distribution. Marketing Science, 19(1), 83-103.

Ma, Y., Chen, G., \& Wei, Q. (2017). Finding users preferences from large-scale online reviews for personalized recommendation. Electronic Commerce Research, 17(1), 3-29.

Maity, M., \& Dass, M. (2014). Consumer decision-making across modern and traditional channels: E-commerce, m-commerce, in-store. Decision Support Systems, 61, 34-46.

Manvi, S. S., Nalini, N., \& Bhajantri, L. B. (2011). Recommender system in ubiquitous commerce. In Proceedings of the 3rd International Conference on Electronic Computer Technology .

Markus, M. L., \& Silver, M. S. (2008). A foundation for the study of it effects: A new look at desanctis and poole's concepts of structural features and spirit. Journal of the Association for Information Systems, 9(10/11), 609-632.

McGrenere, J., \& Ho, W. (2000). Affordances: Clarifying and evolving a concept. In Proceedings of Graphics Interface (GI 2000) (pp. 179186).

McKinsey (2013). Disruptive technologies: Advances that will transform life, business, and the global economy. Retrieved October 03, 2018, from https://www.mckinsey.com/business-functions/digitalmckinsey/our-insights/disruptive-technologies.

Mengxiang, L., Chuan-Hoo, T., Kwok-Kee, W., \& Kanliang, W. (2017). Sequentiality of product review information provision: An information foraging perspective. MIS Quarterly, 41(3), 867-892.

Miles, I. (1990). Teleshopping: Just around the corner? RSA Journal, 138(5403), 180-189.

Nan, G., Yang, J., \& Dou, R. (2017). Do only review characteristics affect consumers' online behaviours? A study of relationship between reviews. Journal of Electronic Commerce Research, 18(4), 330-345.

Nardi, B. (1996). Context and consciousness: Activity theory and humancomputer interaction. Cambridge, MA: MIT Press.

Nassauer, S. (2017, May). 04. Wall Street Journal: Wal-mart wants to know when your milk is about to expire Retrieved January 20, 2019, from https://www.wsj.com/articles/wal-mart-wants-to-knowwhen-your-milk-is-about-to-expire-1493937138.

Ngai, E. W. T., \& Gunasekaran, A. (2007). A review for mobile commerce research and applications. Decision Support Systems, 43(1), $3-15$.

Ngai, E. W. T., \& Wat, F. K. T. (2002). A literature review and classification of electronic commerce research. Information \& Management, 39(5), 415-429.

Nicosia, F. M., \& Mayer, R. N. (1976). Toward a sociology of consumption. Journal of Consumer Research, 3(2), 65-75.

Norman, D. A. (1988). The psychology of everyday things. New York: Basic Books.

Norman, D. A. (1999). Affordance, conventions, and design. Interactions, 6(3), 38-43. 
Oberländer, A. M., Röglinger, M., Rosemann, M., \& Kees, A. (2018). Conceptualizing business-to-thing interactions: A sociomaterial perspective on the internet of things. European Journal of Information Systems, 27(4), 486-502.

Oxford Dictionary (2018). Commerce. Retrieved November 20, 2018, from https://en.oxforddictionaries.com/definition/commerce.

Peng, L., Liao, Q., Wang, X., \& He, X. (2016). Factors affecting female user information adoption: An empirical investigation on fashion shopping guide websites. Electronic Commerce Research, 16(2), 145-169.

Porter, M. E., \& Heppelmann, J. E. (2014). How smart, connected products are transforming companies. Harvard Business Review. Retrieved December 20, 2018, from https://hbr.org/2014/11/howsmart-connected-products-are-transforming-competition.

Pousttchi, K., Tilson, D., Lyytinen, K., \& Hufenbach, Y. (2015). Introduction to the special issue on mobile commerce: Mobile commerce research yesterday, today, tomorrow - what remains to be done? International Journal of Electronic Commerce, 19(4), 1-20.

Prasad, B. (2003). Intelligent techniques for e-commerce. Journal of Electronic Commerce Research, 4(2), 65-71.

Püschel, L., Schlott, H., \& Röglinger, M. (2016). What's in a smart thing? Development of a multi-layer taxonomy. In Proceedings of the International Conference on Information Systems (ICIS 2016) (Article 1005).

Ramaswamy, V., \& Ozcan, K. (2018). Offerings as digitalized interactive platforms: A conceptual framework and implications. Journal of Marketing, 82(4), 19-31.

Rao, B., \& Minakakis, L. (2003). Evolution of mobile kocation-based services. Communications of the ACM, 46(12), 61-65.

Reid, T. (2018). Everything alexa learned in, 2018 Retrieved December 19, 2018, from https://blog.aboutamazon.com/devices/everythingalexa-learned-in-2018.

Romano Jr., N. C., \& Fjermestad, J. (2002). Electronic commerce customer relationship management: An assessment of research. International Journal of Electronic Commerce, 6(2), 61-113.

Rosemann, M. (2014). Proposals for future BPM research directions. In Proceedings of the 2nd Asia Pacific Business Process Management Conference (pp. 1-15).

Rothensee, M. (2008). User acceptance of the intelligent fridge: Empirical results from a simulation. In Proceedings of the $1 s t$ International Conference on the Internet of Things (IOT 2008) (pp. 123-139).

Safi, R., \& Yu, Y. (2017). Online product review as an indicator of users' degree of innovativeness and product adoption time: A longitudinal analysis of text reviews. European Journal of Information Systems, 26(4), 414-431.

Samaras, G. (2002). Mobile commerce: Vision and challenges (location and its management). In Proceedings of the Symposium on Applications and the Internet

Sanchez-Pi, N., \& Molina, J. M. (2009). A multi-agent platform for the provisioning of U-commerce services. NAFIPS 2009-2009 Annual Meeting of the North American Fuzzy Information Processing Society.

Saumya, S., Singh, J. P., Baabdullah, A. M., Rana, N. P., \& Dwivedi, Y. K. (2018). Ranking online consumer reviews. Electronic Commerce Research and Applications, 29, 78-89.

Schierz, P. G., Schilke, O., \& Wirtz, B. W. (2010). Understanding consumer acceptance of mobile payment services: An empirical analysis. Electronic Commerce Research and Applications, 9(3), 209216.

Shang, X., Zhang, R., \& Chen, Y. (2012). Internet of things (iot) service architecture and its application in e-commerce. Journal of Electronic Commerce in Organizations, 10(3), 44-55.
Sharma, S., \& Gutiérrez, J. A. (2010). An evaluation framework for viable business models for m-commerce in the information technology sector. Electronic Markets, 20(1), 33-52.

Shim, J., Avital, M., Dennis, A. R., Rossi, M., Sørensen, C., \& French, A. (2019). The transformative effect of the internet of things on business and society. Communications of the Association for Information Systems, 44(1), 129-140.

Song, Z., Sun, Y., Wan, J., Huang, L., \& Zhu, J. (2017). Smart ecommerce systems: Current status and research challenges. Electronic Markets, 26(3), 473.

Statista. (2018a). Digital shopping device usage and frequency worldwide in, 2017 Retrieved November 20, 2018, from https://www. statista.com/statistics/692846/online-shopping-device-worldwidefrequency/.

Statista (2018b). Retail e-commerce sales worldwide from 2014 to 2021 (in billion U.S. dollars). Retrieved December 10, 2018, from https:// www.statista.com/statistics/379046/worldwide-retail-e-commercesales/.

Strader, T. J., \& Shar, M. J. (1997). Characteristics of electronic markets. Decision Support Systems, 21(3), 185-198.

Timmers, P. (1998). Business models for electronic markets. Electronic Markets, 8(2), 3-8.

Tsalgatidou, A., \& Pitoura, E. (2001). Business models and transactions in mobile electronic commerce: Requirements and properties. Computer Networks, 37(2), 221-236.

Turban, E., King, D., Lee, J. K., Liang, T.-P., \& Turban, D. C. (2015). Electronic commerce: A managerial and social networks perspective (8th ed.). Cham, Heidelberg, New York, Dordrecht, London: Springer.

Uckelmann, D., Harrison, M., \& Michahelles, F. (2011). Architecting the internet of things. Berlin, Heidelberg: Springer.

Vaithianathan, S. (2010). A review of e-commerce literature on India and research agenda for the future. Electronic Commerce Research, 10(1), 83-97.

Vyas, D., Chisalita, C., \& Dix, A. (2017). Organizational affordances: A structuration theory approach to affordances. Interacting with Computers, 29(2), 117-131.

Vygotsky, L. S. (1980). Mind in society: Development of higher psychological processes. Cambridge, MA: Harvard University Press.

Wan, Y., Ma, B., \& Pan, Y. (2018). Opinion evolution of online consumer reviews in the e-commerce environment. Electronic Commerce Research, 18(2), 291-311.

Wan, Y. (2015). The matthew effect in social commerce. Electronic Markets, 25(4), 313-324.

Wan, Y., Menon, S., \& Ramaprasad, A. (2007). A classification of product comparison agents. Communications of the ACM, 50(8), 65-71.

Weber, R. (2012). Evaluating and developing theories in the information systems discipline. Journal of the Association for Information Systems, 13(1), 1-30.

Webster, J., \& Watson, R. T. (2002). Analyzing the past to prepare for the future: Writing a literature review. MIS Quarterly, 26(2), xiii-xxiii.

Wirtz, B. W. (2018). Electronic business (6th ed.). Wiesbaden: Springer Gabler.

Wortmann, F., \& Flüchter, K. (2015). Internet of things. Business \& Information Systems Engineering, 57(3), 221-224.

Xiao, B., \& Benbasat, I. (2007). E-commerce product recommendation agents: Use, characteristics, and impact. MIS Quarterly, 31(1), 137209.

Xu, G., \& Gutierrez, J. A. (2006). An exploratory study of killer applications and critical success factors in m-commerce. Journal of Electronic Commerce in Organizations, 4(3), 63-79.

Publisher's note Springer Nature remains neutral with regard to jurisdictional claims in published maps and institutional affiliations. 